\title{
A tonal analysis of Cologne Schärfung*
}

\section{Carlos Gussenhoven \\ Queen Mary, University of London and Radboud University Nijmegen}

\section{Jörg Peters}

Radboud University Nijmegen

\begin{abstract}
The word prosody of the dialect of Cologne includes a phonological contrast in stressed syllables which at first sight might either reflect a ternary quantity contrast or a binary quantity contrast plus a tone contrast. There are differences in duration as well as F0 between Accent 1 (Schärfung) and Accent 2, along with differences in the intensity profiles of the syllables. It is argued that the contrast is one between an unspecified lexical tone (T) (Accent 2) and no tone (Accent 1), and that the lexical tone assimilates to an intonational tone. We show that a ternary quantity contrast (i) cannot capture the difference between Accent 1 and Accent 2; (ii) would imply an otherwise unattested distributional confinement to the syllable coda of geminate consonants and (iii) would imply unexpected intonation contours in bimoraic syllables. By contrast, a tonal analysis readily accounts for the phonetic and distributional facts.
\end{abstract}

\section{Introduction}

\subsection{General background}

Schärfung ('sharpening') is the traditional term for one member of a lexical phonological opposition in a group of German dialects, of which the dialect of Cologne is representative. ${ }^{1}$ The opposition exists in VV and VN rhymes, where $\mathrm{N}$ stands for a sonorant consonant. Heike $(1962,1964)$

* We would like to thank Alice Tiling-Herrwegen of the Akademie för uns kölsche Sproch for her help with finding speakers and giving us indispensable practical assistance and information. We thank our speakers for giving us their time and best efforts. Our text has greatly benefited from the comments on two earlier versions by two referees and an associate editor, for which we are very grateful. This work was carried out as part of the project Tonale Dialecten van het Nederlands, which is funded by the Vlaams-Nederlands Comité, a joint research foundation of the Fonds voor Wetenschappelijk Onderzoek Vlaanderen (FWO) and the Netherlands Organisation for Scientific Research (NWO).

1 The larger dialect group was identified as Central Franconian (Mittelfränkisch) by Wiesinger (1983). Geographically, it roughly matches the former Rheinprovinz, one of the provinces of the Prussian German states from 1815 to 1945, today 
(a)
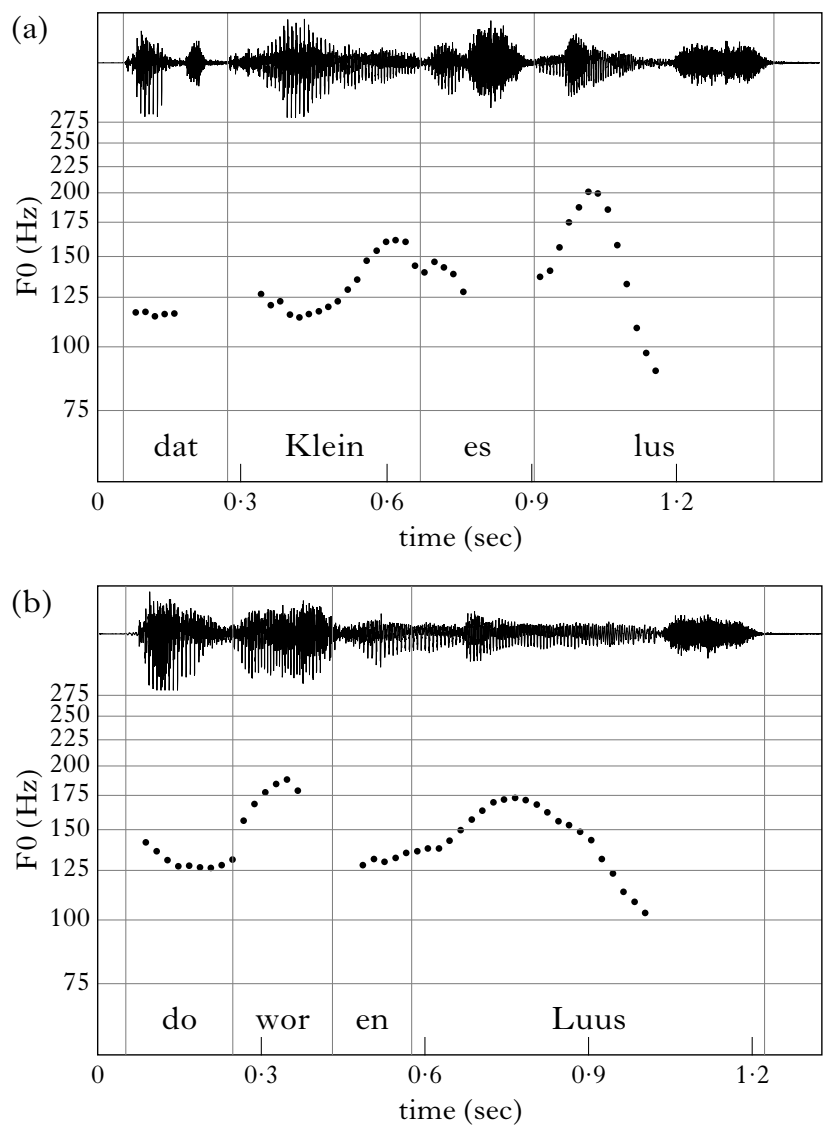

Figure 1

Speech waveforms and F0 tracks of (a) Dat Klein es lus / dat klein es luus/ 'The little one is clever' and (b) Do wor en Luus /do wo on luus/ 'There was a louse', showing differences in the vowel-intensity profile, duration and F0 in the two final syllables (Speaker WJ). Schärfung is illustrated by lus in (a).

lists three phonetic parameters involved in its realisation. First, syllables with Schärfung are shorter than syllables without. Second, syllables with Schärfung show a relatively fast decay of the intensity envelope of the sonorant portion of the rhyme. Third, the fundamental frequency (F0) shows a steep fall in syllables with Schärfung, while syllables without tend to have more level F0 contours. All three differences can be observed in Fig. 1, which shows the contrast in the minimal pair lus 'clever' $\sim$ Luus 'louse'. '

comprising the southern half of North Rhine-Westphalia and the northern half of Rhineland-Palatinate (Newton 1990). The word-accent contrast in this dialect was among the first to be investigated acoustically (Heike 1962, 1964, 1988).

2 In this article we use the orthography proposed by Wrede (1956-58), which is still regarded as the standard orthography for the dialect. Note that the different 
The issue addressed in this paper is which of these three phonetic parameters is primary in the sense of directly expressing the phonological feature involved, and which two are there to enhance that primary parameter (Stevens \& Keyser 1989). One of these can be quickly dismissed: the difference in intensity profile cannot be related to any known phonological feature except perhaps stress, i.e. foot structure. Since there is no difference in stress between syllables with and without Schärfung in any interpretable way, the difference in the intensity profile must be an enhancing feature. While it is by no means consistently present in Accent-1 syllables and does not give the impression of glottalisation when it is, the fall-off in intensity has the auditory effect of making the vowel sound short, much as does the glottal closure before voiceless coda stops in English. If the phonetic duration difference is primary, the opposition concerns a quantity contrast, in which case the F0 differences are derived. If the F0 difference is taken to be primary, the opposition concerns a lexical tone contrast, with the durational differences arising as a result of contrast enhancement.

At first sight, the data lend themselves either to a quantity or a tonal analysis. Estonian provides a case in which it has proved difficult to choose between a quantity and a tonal interpretation of a contrast (Fox \& Lehiste 1989, Lehiste \& Fox 1992). From a quantity perspective, there is a threeway contrast on (non-final) stressed syllables, as shown in (1), with an intonational difference being predictable from the contrast between bimoraic and trimoraic syllables. In this interpretation, the realisation of the high tone of an intonational pitch accent $\mathrm{H}^{*} \mathrm{~L}$ would cover the long vowel in (1b), while in (1c) at least part of the fall due to the $\mathrm{L}$ tone is realised within the vowel. From a tonal perspective, there is a two-way contrast between short and long vowels ((1a) vs. (1b, c)), with a tonal contrast on long vowels. Perceptual data point to an ongoing change in the direction of a tonal analysis (Lehiste 2003).

(1)

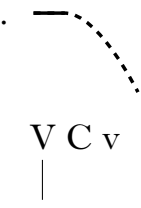

H L b.

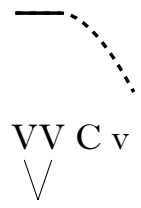

$\mathrm{H} \mathrm{L}$
C.

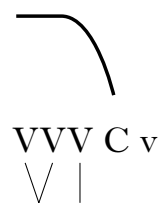

H L

We argue that a quantity analysis must be rejected for the dialect of Cologne. There are four distributional arguments. First, a quantity analysis leads to a typologically unexpected distribution of a geminatesingleton contrast. Second, a quantity analysis yields syllable types whose analysis is ambiguous between VVVC and VVCC. Third, a quantity analysis is incapable of capturing either member of the opposition as a natural

spellings of lus and Luus do not indicate a difference of vowel length. An alternative orthography has recently been proposed by Bhatt (2002). 


\section{Carlos Gussenhoven and Förg Peters}

class. Finally, a quantity analysis leads to a counterintuitive characterisation of the enhancement of the (putative) contrast between long and overlong syllables by F0. We will present comprehensive phonetic data and show that these are readily explained by a tonal representation, and will propose a first phonological analysis.

\subsection{Segmental structure}

If we abstract away from Schärfung, the Cologne dialect has full sets of long and short versions of ten monophthongal vowel qualities. Unlike the standard language, the dialect consistently has the same vowel qualities in the long and short versions. In addition, it has six diphthongs. This vowel system of 26 nuclei is given in (2).

\begin{tabular}{|c|c|c|c|c|c|}
\hline \multirow[t]{2}{*}{$(2)$} & $\mathrm{y}$ & $\mathrm{u}$ & ii & yy & $\mathrm{uu}$ \\
\hline & $\varnothing$ & $\mathrm{O}$ & ee & ØØ & OO \\
\hline & $œ$ & J & $\varepsilon \varepsilon$ & œœ & כנ \\
\hline & & & & & \\
\hline & & & $\varepsilon \dot{i}$ & œy & ou \\
\hline & & & ai & ગi & כu \\
\hline
\end{tabular}

The contrasts between the short high and high mid series may be merged to the / I Y U/ of standard German, according to Heike (1964). However, our speakers had all these distinctions, as in widder /'vidər/ 'again', wedder /'vedər/ 'weather', Füss /fys/ 'foxes', Schöss / øøs/ 'shots', Fuss /fus/ 'fox', Schoss / Jos/ 'shot'. Minimal pairs for long and short vowels are provided by, for instance, Vü̈s /fyys/ 'fists' Füss /fys/ 'foxes', Vuus /fuus/ 'fist' $\sim$ Fuss /fus/ 'fox' and Dat/daat/ 'deed' $\sim$ dat /dat/ 'that'.

The consonant system is given in (3).

(3) $\begin{array}{ccccc}\mathrm{p} & \mathrm{t} & & \mathrm{k} & \\ \mathrm{b} & \mathrm{d} & & \mathrm{g} & \\ \mathrm{f} & \mathrm{s} & \int & \mathrm{x} & \mathrm{h} \\ & \mathrm{z} & 3 & & \\ & \mathrm{ts} & & & \\ \mathrm{m} & \mathrm{n} & & \mathrm{y} & \\ \mathrm{v} & \mathrm{l} & \mathrm{j} & & \mathrm{R}\end{array}$

As in German and Dutch generally, final devoicing prevents voiced obstruents from appearing in the coda. In addition, $/ \mathrm{j} \mathrm{h} /$ are illicit in the coda, while $/ \mathrm{y} /$ does not occur foot-initially. ${ }^{3}$ A number of historical sound changes distinguish the system from that of standard German. The voiced velar plosive $/ \mathrm{g} /$ merged with $/ \mathrm{R} /$, which varies between a voiced uvular

3 The usual transcription of $/ v /$ is $/ v /$ in the literature, but the consonant has little if any friction and we thus prefer to represent it as an approximant. 
trill and a voiced uvular fricative, when it forms the onset of a weak syllable after a long back vowel, as in Mage/'maaRa/ 'stomach', frage /'fR JoRə/ 'to ask', and merged with approximant / $\mathrm{j} /$ in other contexts, as in lige /'lija/ 'to lie down', lege /'lejə/ 'to tell untruths', geseech /ja'zeeJ/ 'face', jääl /jecl/ 'yellow', all of which correspond to /g/ in German. Velar / k g y/ developed from $/ \mathrm{t} \mathrm{d} \mathrm{n/} \mathrm{after} \mathrm{high} \mathrm{long} \mathrm{vowels,} \mathrm{with} \mathrm{concomitant} \mathrm{shortening}$ of the vowel, as in Zigg/tsik/ 'time', ligge/'liga/ 'to suffer', Wing/vin/ 'wine'. The segment $/ \mathrm{x} /$, from earlier $/ \mathrm{k} /$, occurs in the coda or in the onset of the weak syllable following a long vowel, as in maache /'maaxa/ 'to make'. After front vowels, $/ \mathrm{x} /$ is strongly fronted, and coalesces with $/ \mathrm{J} /$. Thus, in the back vowel context, /aaf/ 'arse' contrasts with /aax/ 'eight',

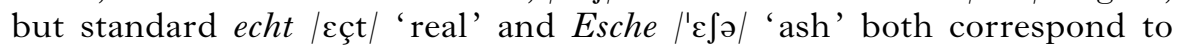
Cologne $/ \varepsilon \int / . / 3 /$ only occurs in loans, where it may vary with $/ \mathrm{J} /$, as in Mart Sargeant/maat Jar'zant/ 'market superintendent', genant/3ə'nant/, / Ji'nant/ 'embarrassing'.

\subsection{The Cologne contrast}

Schärfung creates a lexical contrast that corresponds to Accent 1 in Dutch and German tonal dialects (Hermans 1985, Schmidt 1986, Gussenhoven \& van der Vliet 1999, Gussenhoven 2000a), and we will from now on refer to 'Accent 1' and 'Accent 2', which we indicate by superscript numbers after the sonorant rhyme of the stressed syllable. As in many of these dialects, the contrast only occurs in words whose stressed syllable contains at least two sonorant moras, i.e. a long vowel, a diphthong or a short vowel and a sonorant consonant ([m n $\mathrm{gl}] \mathrm{R}]$ ). It is used both to distinguish between lexemes, as in (4a), and derivational and inflectional forms of single stems. (4b) shows a derivational contrast, an inflectional contrast between dative and nominative singular and one involving plural and singular forms, from Tiling-Herrwegen (2002: 125). ${ }^{4}$

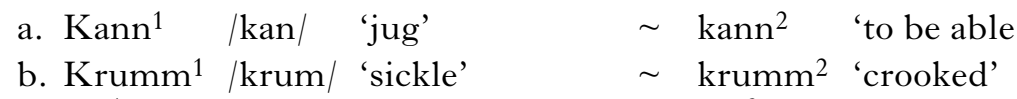
$\mathrm{Da}^{1} \mathrm{ch} /$ daax/ 'day + SG + DAT' $\sim \mathrm{Da}^{2} \mathrm{ch}$ 'day + SG + NOM'
Sching ${ }^{1} /$ Sin/ 'certificate + PL' $\sim$ Sching $^{2}$ 'certificate + sG'

Thus, three-way distinctions of the type in (5a) exist, while a four-way distinction exists in rhymes with sonorant coda consonants, as shown in $(5 b)$.

${ }^{4}$ While Limburgian dialects of the Netherlands and Belgium tend to have some ten to fifteen monosyllabic nouns with Accent 1 in the plural and Accent 2 in the segmentally identical singular, we have come across only five cases in the Cologne dialect. In addition to Sching, we found /troon/ Tron 'tear' (Schumacher, ms), /knin/ Kning 'rabbit' (Bhatt 2002: 25), /'derəm/Därm 'intestines' and /daax/Dach, a plural form segmentally identical to the singular and existing alongside $/$ decx/ Däch and /'daara/ Dage 'day' (Heike 1964). 


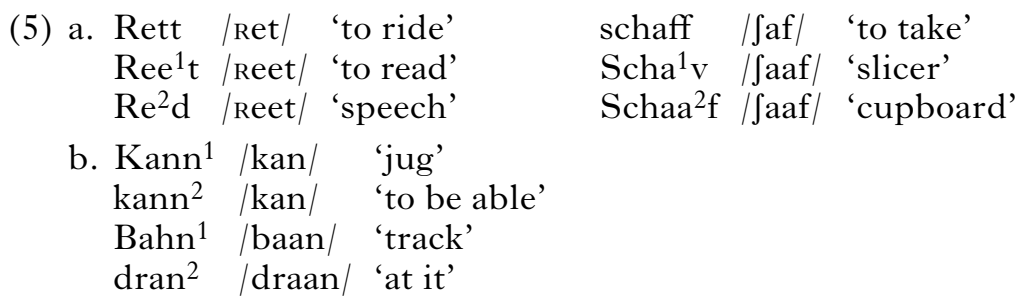

Unlike the Dutch dialect of Maastricht, where a tone contrast co-occurs with a subset of its vowels (Gussenhoven \& Aarts 1999), all 26 vowel nuclei of the Cologne dialect can occur with Accent 1 and Accent 2. For instance, there is a four-way contrast for front unrounded diphthongs, as shown by $S c h n e i^{1} /$ Jnei/ 'snow', $d r e i^{2} / \mathrm{d} \varepsilon \varepsilon \mathrm{i} /$ 'three', $B e i^{1}$ /bai/ 'bee', $E i^{2}$ /ai/ 'egg'.

Before dealing with the question of whether the difference between Accent 1 and Accent 2 is to be regarded as a quantity or a tonal contrast $(\S 3)$, we require more detailed information on the realisation of the contrast in different prosodic conditions. To this end, we summarise the results of a production experiment with six speakers in $\$ 2$. A fuller report will appear as Peters (forthcoming).

\section{Materials}

To understand how the Cologne word accents interact with prosodic context, we created minimally different pairs of test sentences, using the minimal pairs in (6).

(6) /luus/ lu's 'clever' /kan/ Kann ${ }^{1}$ 'can, bottle' kann $^{2}$ 'be able' /braut/ brau ${ }^{1} \mathrm{t}$ 'brews + 3sG + PRES' Brau ${ }^{2} \mathrm{t}$ 'bride'

We varied the following contextual factors:

(7) a. the pragmatic condition for the carrier sentence ('declarative', 'interrogative', 'continuative')

b. the accentuation status of the target word (nuclear, prenuclear, postnuclear)

c. the distance of the target word to the end of the IP (antepenultimate, penultimate, ultimate)

We mainly report data from two speakers, $\mathrm{AH}$, a 40 -year-old female, and $\mathrm{WJ}$, a 60 -year-old male, using data including the minimal pairs in (6), as well as from an additional corpus of sentences with words containing one sonorant mora in the stressed syllable (see Appendix). In $\$ 3$ we investigate the plausibility of a quantity analysis and find against it. In $\S 4$, we demonstrate the correctness of a tonal analysis. $\$ 5$ attempts to explain the prominent role of duration in the implementation of the contrast, 
while $\$ 6$ contains brief comparisons with some other word-prosodic contrasts in European languages.

\section{Why a quantity analysis is not viable}

A quantity analysis would characterise the first set of words in (5a) as in $(8 a)$, and those in $(5 b)$ as in $(8 b)$.

(8)

$\begin{array}{lll}\text { a. One sonorant mora } & \text { Accent } 1 & \text { Accent } 2 \\ \text { Rett /Ret/ } & \operatorname{Ree}^{1} \mathrm{t} / \mathrm{Reet} / & \operatorname{Re}^{2} \mathrm{~d} / \mathrm{Reeet} / \\ \text { b. Accent } 1 & \text { Accent } 2 & \\ \mathrm{Kann}^{1} / \mathrm{kan} / & \mathrm{kann}^{2} / \mathrm{kann} / & \\ \mathrm{Bahn}^{1} / \mathrm{baan} / & \mathrm{dran}^{2} / \mathrm{draaan} / \text { or } / \text { draann/ }\end{array}$

In the three subsections below, we consider the plausibility of this analysis from the point of view of the durational data, the distributional data and the F0 data.

\subsection{Duration and the quantity analysis}

In Fig. 2, we show durations of sonorant portions of rhymes with Accent 1 and Accent 2 in a number of positions, pooled over six speakers and five words for each tone accent. These data show four durational effects which have been reported for other tonal and non-tonal West Germanic languages. First, sonorant rhymes with Accent 2 are longer than otherwise identical sonorant rhymes with Accent 1 . This effect is the durational component in the complex of phonetic features traditionally referred to as Schärfung, which we here term 'Accent-2 lengthening'. It occurs in all positions: in final and antepenultimate positions in the IP, both accented and unaccented, as well as in prenuclear position. ${ }^{5}$ Second, rhymes in pitch-accented syllables are longer than in unaccented syllables, as shown by a comparison between the nuclear and postnuclear data. This 'accentual lengthening' has been found for a number of Germanic languages

5 Against the background of the neutralisation of the etymologically equivalent opposition in the dialects of Venlo and Roermond (Gussenhoven \& van der Vliet 1999, Gussenhoven 2000a), this unrestricted distribution may at first sight appear to support a quantity analysis. In those Dutch dialects, the opposition is maintained in IP-final syllables and accented IP-medial syllables only. The neutralisation in IPmedial non-accented positions can be explained as a tonal effect, since in those neutralising positions, no intonational tones co-occur with the syllables, as opposed to accented syllables, which have a pitch accent $\mathrm{T}^{*}$, and final syllables, which at least have a boundary tone. Interestingly, in a dialect in which the equivalent opposition is evidently a quantity contrast, that of Weert in the Netherlands, no such neutralisation takes place (Heijmans 2003, Fournier et al. 2004). In not neutralising the contrast, the Cologne dialect agrees with that of non-tonal Weert. However, there have also been reports of tonal dialects, like Maastricht and Tongeren (Gussenhoven \& Aarts 1999, Heijmans 1999), which maintain the contrast in all prosodic positions, so that there is no basis for an argument. 


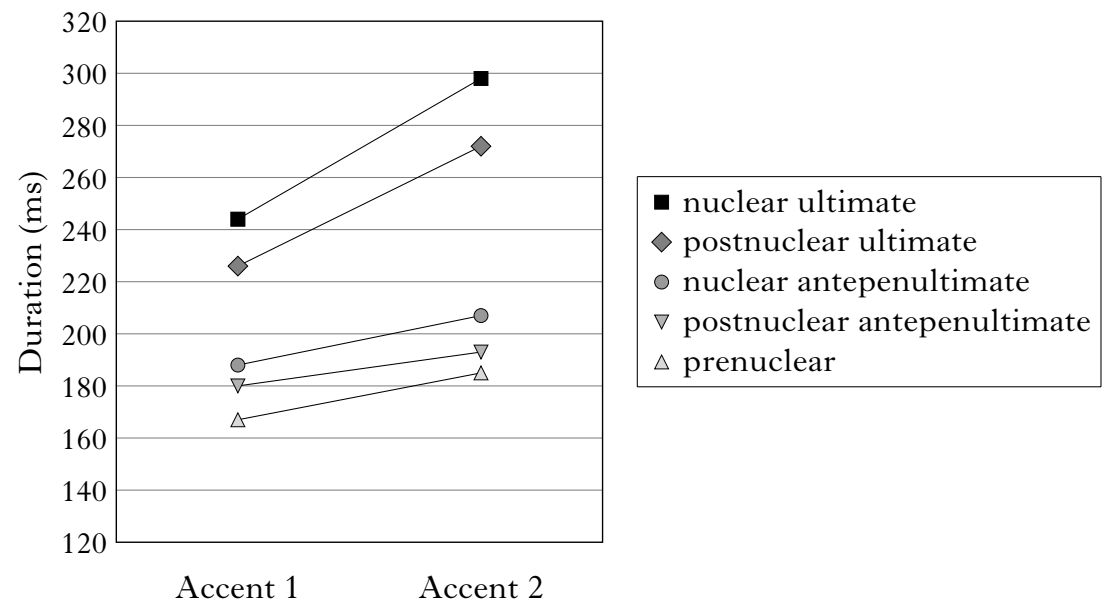

Figure 2

Durations of sonorant portions of rhymes with Accent 1 and Accent 2 in nuclear position, in postnuclear ultimate and antepenultimate positions, and in prenuclear position. The data are pooled over six speakers for the target words listed in $(8 \mathrm{a})(\mathrm{N}=15,9$ and 3 for the nuclear, postnuclear and prenuclear conditions, respectively).

(Cambier-Langeveld \& Turk 1999). The effect is probably due to the more precise articulation in accented words (cf. de Jong 1995). Third, a comparison of the ultimate and antepenultimate data shows that the Cologne dialect has 'final lengthening' over and above 'accentual lengthening', adding the two effects, as in British English (Cambier-Langeveld $\&$ Turk 1999). Fourth, the data show that syllable rhymes in prenuclear position are shorter than in other positions, whether final or antepenultimate, showing that prenuclear parts of utterances are spoken faster than the stretch including the nuclear syllable and the postnuclear syllables (cf. Nooteboom 1972).

What is new in these data is the disproportionate amount of final lengthening applied to Accent-2 rhymes in IP-final position, as compared to rhymes with Accent 1 . While IP-final Accent-1 rhymes are some $30 \%$ longer than rhymes in nuclear antepenultimate position, sonorant rhymes with Accent 2 are $44 \%$ longer. In the postnuclear condition, these figures are $26 \%$ and $41 \%$, respectively. We are not aware that final lengthening is exponential. Indeed, bimoraic sonorant rhymes with Accent 1 do not undergo more final lengthening than monomoraic sonorant rhymes. This can be seen in Fig. 3, which shows durations of sonorant rhymes with Accent 1 in the same panel as those for monomoraic syllables. The monomoraic rhymes in accented IP-final position add some $27 \%$ to the duration of rhymes in antepenultimate position, the Accent- 1 rhymes add $22.5 \%$. In the non-nuclear condition, the monomoraic rhymes add $29 \%$, the Accent-1 rhymes only $11 \%$. Thus, on the basis of a comparison 

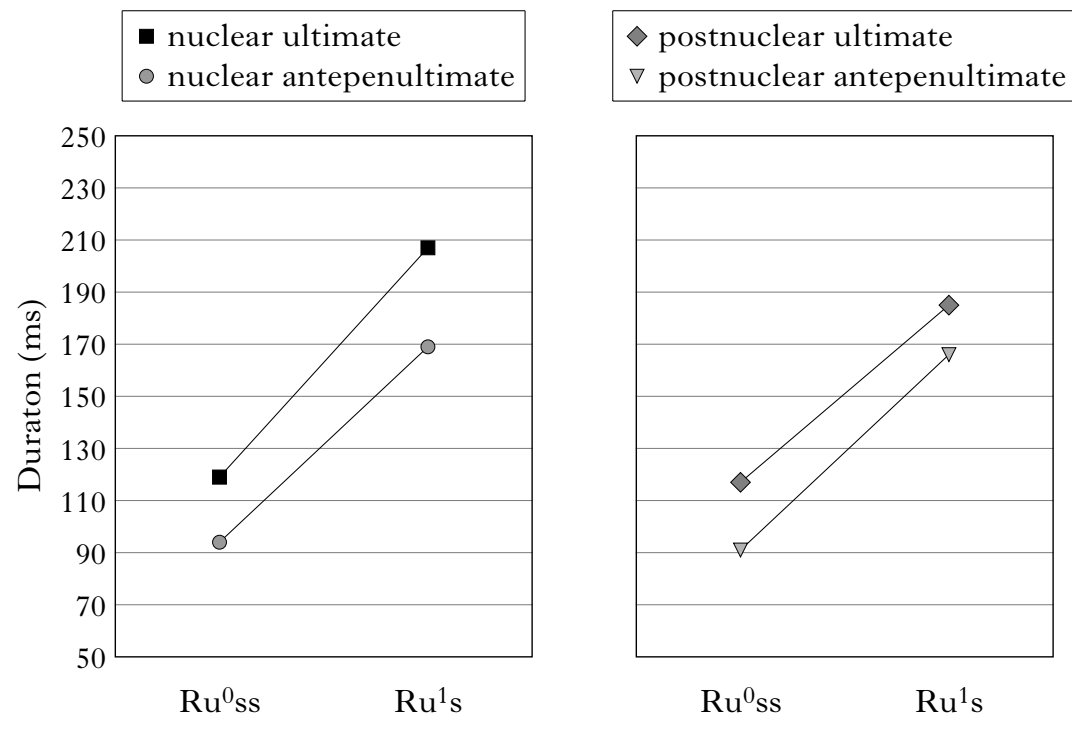

Figure 3

Durations of sonorant portions of monomoraic rhymes (Russ) and bimoraic rhymes with Accent $1\left(R u^{1} s\right)$ in nuclear (left panel) and postnuclear (right panel) ultimate and antepenultimate position. The data are pooled over the speakers $\mathrm{AH}$ and $\mathrm{WJ}(\mathrm{N}=6)$.

between monomoraic and bimoraic syllables, we conclude that the addition of a mora does not lead to an increased effect of final lengthening. Therefore, if the disproportionate amount of final lengthening of Accent 2 is due to a third mora, this would create a quite unexpected implementation of a trimoraic syllable.

\subsection{Distributional facts and the quantity analysis}

Distributional facts argue against a quantity analysis in a number of ways. First, at least one of the members of the opposition must be a natural class. For one thing, the contrast is highly salient for native speakers, who divide stressed syllables up into those with Schärfung and other syllables, the latter group comprising both syllables with one sonorant mora and Accent-2 syllables with two. ${ }^{6}$ This intuition is reflected in Wrede

6 As pointed out by the associate editor, the fact that native speakers distinguish syllables with Schärfung from syllables without Schärfung implies that they neither group syllables without lexical tone together (those with one sonorant mora and those with two but without lexical tone) nor single out the group with lexical tone (those with two sonorant moras and lexical tone). In our analysis, however, the 'marked' class is the syllable with two moras and Accent 2. Probably, the native speakers' intuition is based on the phonetic complex of fast F0 movement, shortening and intensity drop required for Accent 1 . Phonologically, this type of syllable is distinct both from the monomoraic cases and from syllables with Accent 2, in that 


\section{Carlos Gussenhoven and Förg Peters}

(1956-58), who only indicates Accent 1 , as well as in the older literature. For another, the realisation of intonational pitch accents on syllables with Accent 1 differs from that in other syllables, as detailed in $\S 4$. While one or both groups of syllables will therefore need to be referred to, this is impossible in a quantity analysis. The spoilsport structure that makes a simple division into bimoraic and trimoraic rhymes impossible is the $B a h n^{1}$ type in (8b), which contains three sonorant moras, yet has Accent 1 . Accent 1 would be characterised by minimally two sonorant moras, which must not include either a trimoraic vowel or a geminate consonant, a characterisation that does not allow a single, non-disjunct statement. Accent 2 would minimally have three sonorant moras which contain either a trimoraic vowel or a geminate, again a characterisation involving a disjunction.

A second distribution-based objection is that the quantity system would be typologically rare. It may not be the three-way quantity contrast by itself that seems problematic, since this is attested for Low German dialects in the Hamburg area (Wiesinger 1983), but rather the implication that in addition to the three-way vowel quantity contrast there would be a geminate-singleton contrast in the coda. This geminate contrast would exist to the exclusion of geminates in word-medial position, which is typologically the most common position for geminates (Kraehenmann 2003 : 220). Incongruously, it would imply that underlying coda geminates lose their geminate status whenever they are placed in intervocalic position. Heike (1964: 110) points out, for instance, that an Accent-2 word like kann' 'is able' in (9a) no longer has this word accent in (9b), where clitic et causes the coda [n] to occur in the onset of a syllable. Moreover, languages with a geminate-singleton contrast for sonorants but not for obstruents are rare, though not unknown. Of the 317 languages represented in Maddieson (1984), Chuvash, Ocaina and !Xu have at least one geminate sonorant without having any geminate obstruents. ${ }^{7}$
a. hä kann ${ }^{2}$
/hes kann/
'he is able'
b. hä kann ${ }^{0}$ et
/heع kanət/
'he is able to do it'

A third distribution-based argument is that structures such as $\mathrm{dran}^{2}$ in (8b) are uncomfortably indeterminate with regard to the two analyses of their rhyme, i.e. VVVC and VVCC. Finally, the putative existence of bimoraic and trimoraic diphthongs, as in (10), might be considered a fourth argument against a quantity analysis, since it does not occur in the 317-language corpus of Maddieson (1984). However, it has been reported for north German (Wiesinger 1983) and Scottish Gaelic (Ternes 1989).

the trailing tone of the pitch accents $\mathrm{H}^{*} \mathrm{~L}$ and $\mathrm{L}^{*} \mathrm{H}$ associates with a mora. It is our impression that, like sociolinguistic stereotypes, phonological categories which native speakers are aware of tend to be 'surfacy', and salient.

7 Seven languages in the corpus have unaspirated geminate $[\mathrm{p} \mathrm{t}]$ and nine a geminate $[\mathrm{k}]$; for $[\mathrm{m} \mathrm{n}]]$ the numbers are eleven, six and two, and for $[1 \mathrm{k}]$ four and none, respectively. 
A tonal analysis of Cologne Schärfung 261
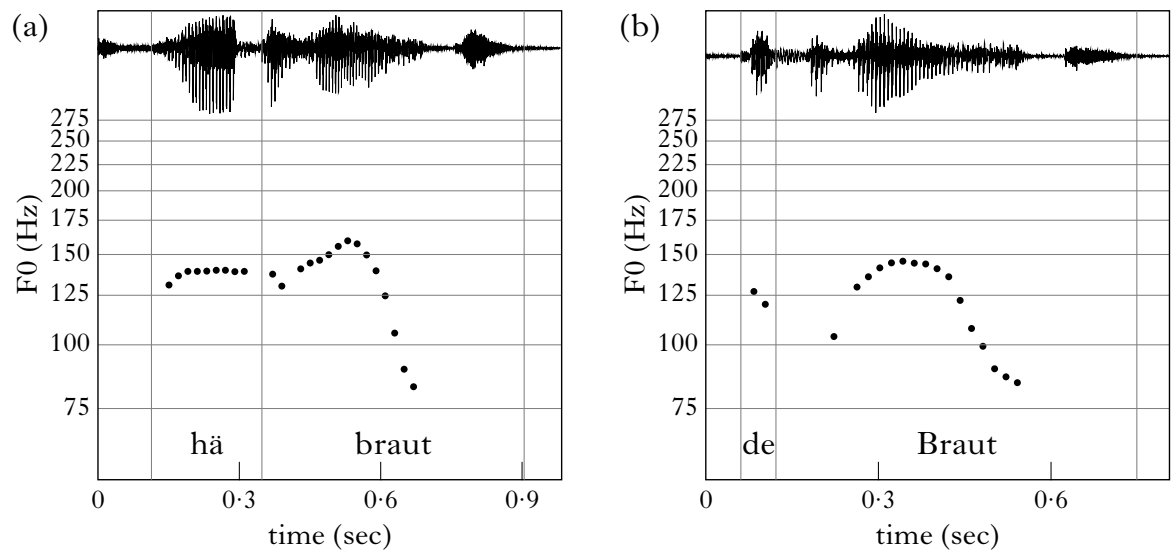

Figure 4

Speech waveforms and F0 tracks of (a) Hä brau't $t$ /hec braut/ 'He brews' and (b) de Brau²t/də braut/ 'the bride'. Speaker WJ.

But in this case, too, there would be ambiguity in the analysis, in that (10b) might equally be /də brauut/.

(10) a. hä brau't /heع braut/ 'he brews'

b. de $\mathrm{Brau}^{2} \mathrm{t}$ /də braaut/ 'the bride'

\subsection{F0 and the quantity analysis}

Most of the observations in the literature about the pitch contours of the two word accents concern declarative pronunciations. These generally show a pitch fall in or after the accented syllable, which we provisionally analyse as due to a pitch accent $\mathrm{H}^{*} \mathrm{~L}$. Figures 4 and 5 present the wordaccent contrast in this condition in IP-final and IP-internal positions, respectively. In IP-final position, the contours reveal a falling pattern, as shown in Fig. 4, but the fall for Accent 2 in (b) starts later in the vowel than in the case of Accent 1 in (a), allowing the high pitch to cover a larger proportion of the vowel. The same minimal pair appears in nuclear position IP-internally in Fig. 5. Accent 1 falls, just as in IP-final position, while Accent 2 has high level pitch, forcing all of the fall to take place on the postnuclear word $s \ddot{a}^{1} t$.

In a quantity analysis, the contours in Fig. 5 would have to be analysed as in (11a) and (11b), respectively. While the difference between the IPfinal contours in Fig. 4 might conceivably be accounted for in the phonetic implementation by timing the fall with the end of the IP, we cannot assume that the difference between (11a) and (11b) is due to the phonetic implementation. If it was, more comparable timings of the fall in the bimoraic and trimoraic conditions would be expected. In (11b), spreading of $\mathrm{H}$ is therefore assumed to account for the late occurrence of the fall. 

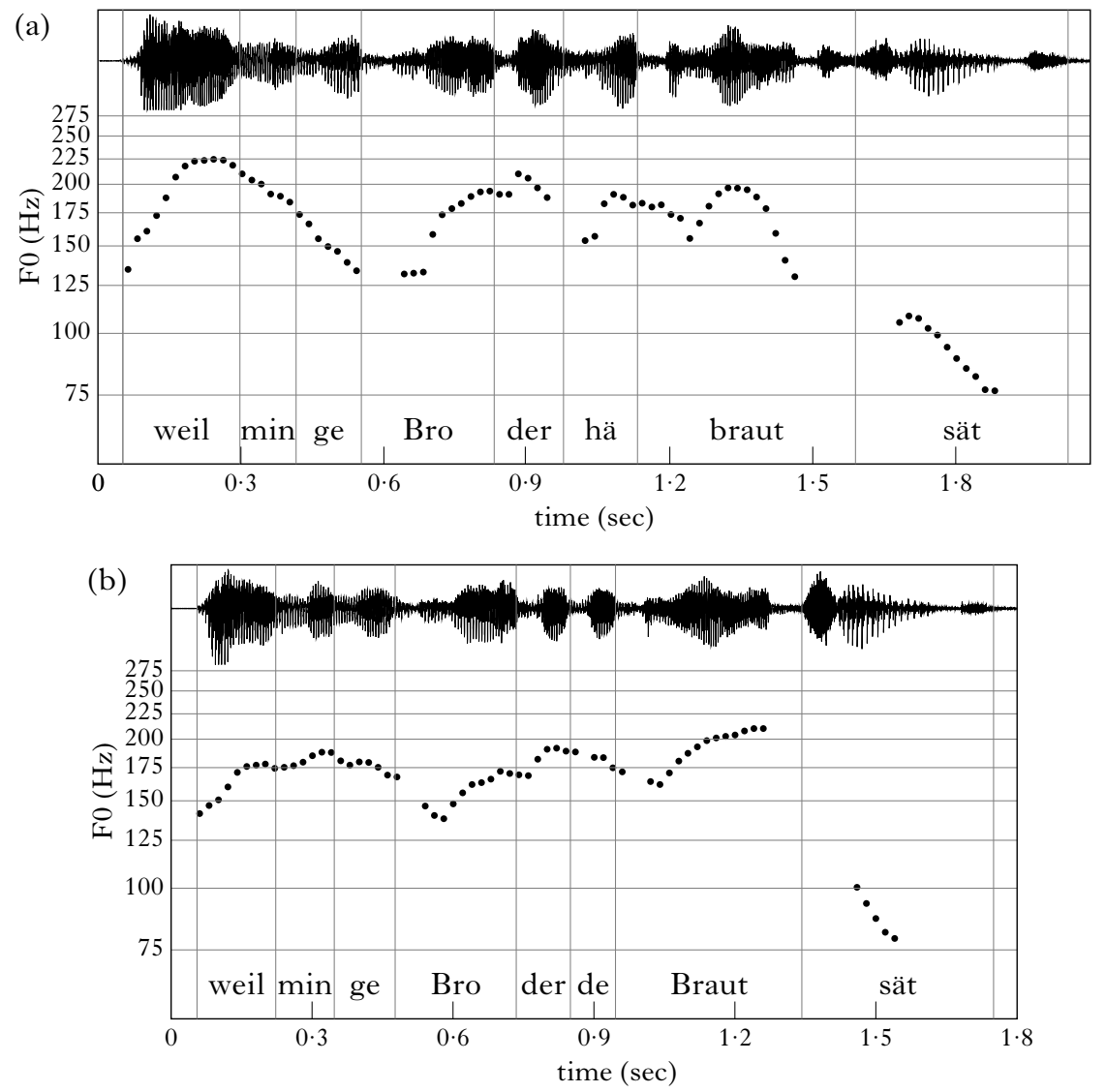

Figure 5

Speech waveforms and F0 tracks of (a) weil minge Brolder 'hä brau ${ }^{1} t^{\prime}$ ' $\ddot{a}^{1} t /$ weil

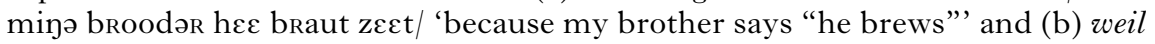

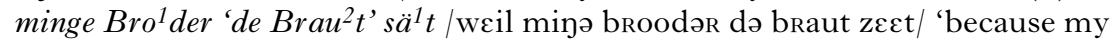
brother says "the bride"'. Speaker WJ.

What is odd about these representations is the need for the spreading of $\mathrm{H}^{*}$ just in case there are three sonorant moras; when there are two, $\mathrm{H}^{*}$ does not spread, but leaves the second sonorant mora for the trailing L. A spreading rule that spreads tones only if more than one free TBU is available would appear to be otherwise unattested. 


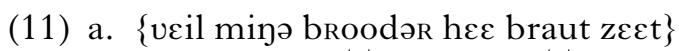

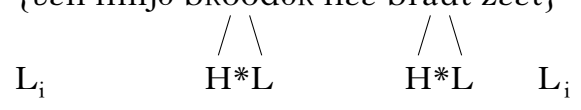

weil minge Bro ${ }^{1}$ der 'hä brau ${ }^{1} t^{\prime}$ sä ${ }^{1} t$ 'because my brother says "he brews"”

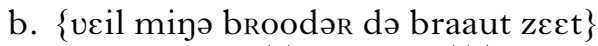

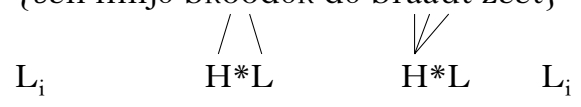

weil minge Bro' der 'de Brau $^{2} \mathrm{t}$ ' sä ${ }^{1} \mathrm{t}$

'because my brother says "the bride",

Since the quantity analysis faces an atypical durational implementation and fails to capture Accent 1 as a natural class, while yielding a highly unusual distribution of geminates and a highly marked tone-spreading rule, we abandon the quantity hypothesis and turn to a tonal analysis.

\section{A tonal analysis}

A tonal analysis would characterise the Cologne dialect as having a binary quantity contrast plus a tone contrast in main stressed syllables with two sonorant moras. Since it is common for tones to increase the duration of syllables they occur on, it seems reasonable to assume a tone is used to represent Accent 2, while Accent 1 is toneless. This is in line with analyses of the word-accent contrast in the tonal dialects of Venlo, Roermond, Maastricht and Tongeren mentioned earlier. Under this option, (11a) would retain its analysis, while (11b) might be as in (12). Here, the level pitch over the vowel /au/ is due to a lexical $\mathrm{H}$ tone that combines with the intonational pitch accent $\mathrm{H}^{*} \mathrm{~L}$. The assumption that sonorant moras are TBUs would appear to give the desired results: a steep fall for Accent 1 , and level high pitch for Accent 2 . Unlike the case in the quantity analysis, there is nothing unexpected about the realisation of Accent 2 in IP-internal position, while in IP-final position, the contrast between $\mathrm{H}^{*} \mathrm{~L} \mathrm{~L}_{\mathrm{i}}$ and $\mathrm{HH}^{*} \mathrm{~L} \mathrm{~L}_{\mathrm{i}}$ adequately predicts the relatively late timing of the fall in IP-syllables with Accent 2 (cf. Fig. 4).

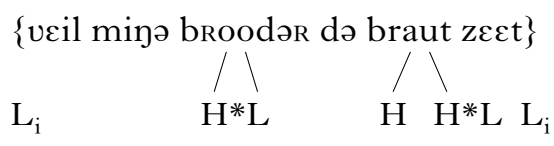

In the tonal analysis, the fact that Accent 2 undergoes disproportionate final lengthening is no longer surprising. It means that Accent2 lengthening is sensitive to the prosodic context, and is more extreme in 


\section{Carlos Gussenhoven and Förg Peters}

IP-final position than in IP-internal position. Accent-2 lengthening is a case of tonal lengthening. While such tone-induced duration is typically attributable to the longer time that contour tones require (Zhang 2000), as for instance in Swedish, where citation pronunciations of trochees with Accent 2 are longer than trochees with Accent 1 (e.g. $a n^{2} d e n$ 'the ghost' with surface HLHL vs. an ${ }^{1}$ den 'the duck' with surface LHL; Lyberg 1981), in the case of the dialect of Cologne the tone-induced lengthening is phonetically arbitrary, but evidently functional.

The distributional facts follow naturally from the analysis. Accent 1 is a rhyme with two sonorant moras without lexical tone, while Accent 2 has two sonorant moras with a lexical tone. Syllables with one sonorant mora cannot have the contrast. If we assume that these syllables are lexically toneless, the loss of Accent 2 in cliticisation contexts is explained by the impossibility of maintaining a lexical tone in a syllable with one sonorant mora. The $/ \mathrm{n} /$ of $\mathrm{kann}^{2}$ in (13a), which occupies the second sonorant mora in the non-cliticised case, is an onset consonant or an ambisyllabic consonant after et has been included in the prosodic word to its right, as shown in (13b) (cf. (9)). Hermans (1985) notes a parallel derivational process that has just this effect in the Maasbracht dialect. In neither dialect can word-internal or cliticised structures of the type VNV have the word-accent contrast.

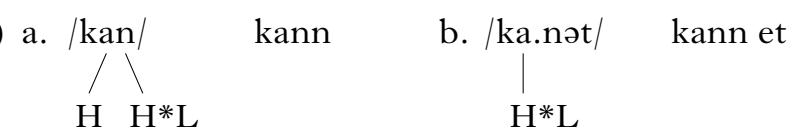

It would therefore appear that the distinction is tonal.

Now that we have established the tonal nature of the contrast, three questions arise. The first concerns the value of the tone. An important reason for the Cologne dialect looking superficially like one with a durational distinction between the word accents is that, if we abstract away from timing differences, there are no pitch movements which are unique to either accent. We will argue in $\S 4.1$ that this is because the lexical tone is unspecified, and assimilates to an adjacent intonational tone. In $\$ 4.2$, we show that in addition to accented syllables, this could be argued to be true also for postnuclear (unaccented) ones; here, too, the lexical tone chameleonically effaces its pitch manifestation within the postnuclear stretch. In $\S 4.3$, we consider the issue of the TBU, and argue that, as in Venlo and Roermond, the TBU in Cologne is the sonorant mora.

\subsection{The value of the lexical tone}

In the declarative accented pronunciations shown in Figs 4 and 5, the lexical tone is clearly $\mathrm{H}$. This is also true for prenuclear realisations, which are no different from the IP-internal nuclear ones shown in Fig. 5. In Fig. 6a a fall occurs inside the syllable with Accent 1 , the adjective $l u^{1} s$, 

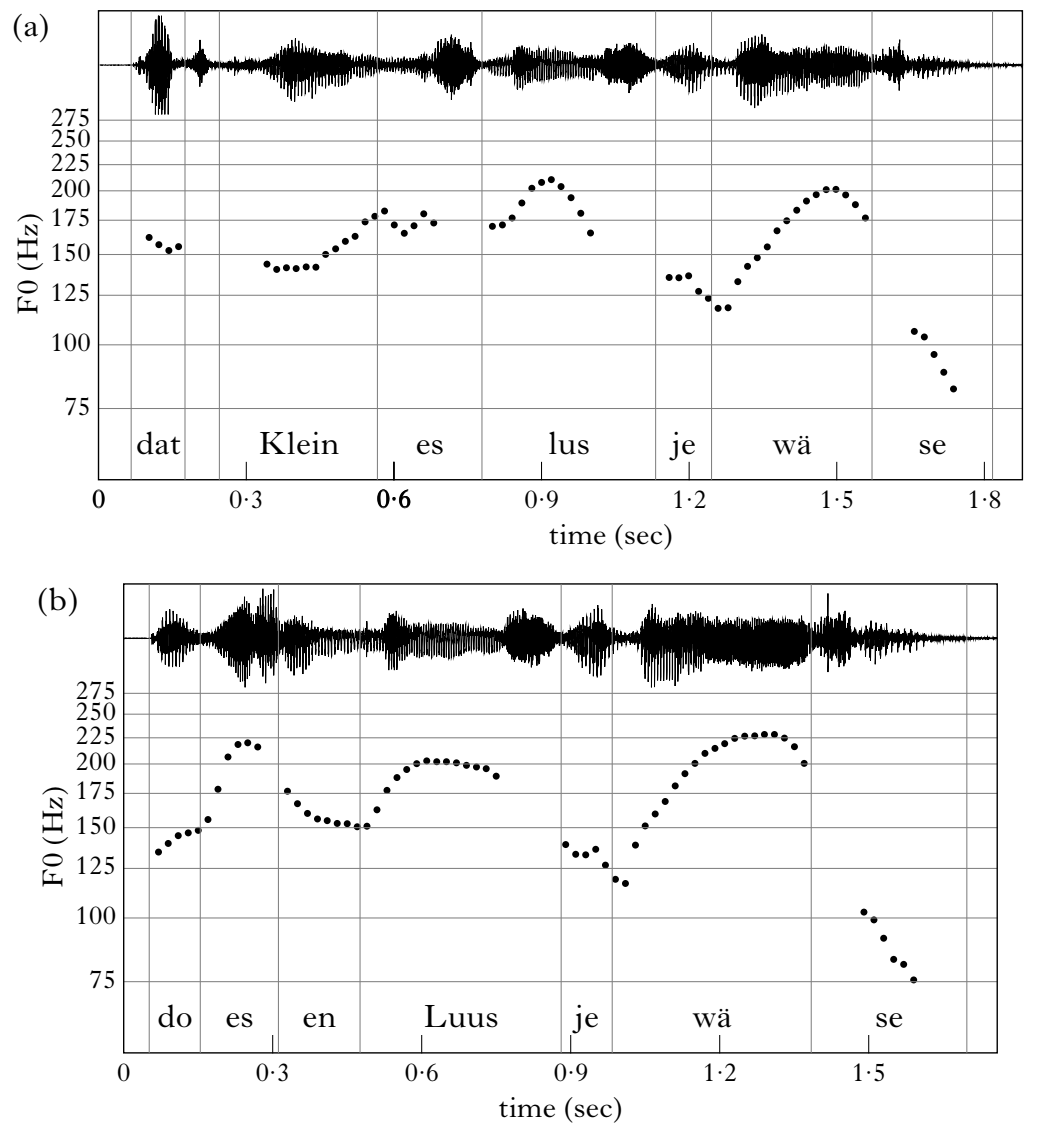

Figure 6

Speech waveforms and F0 tracks of (a) Dat Klein ${ }^{1}$ es $l u^{1}$ s jewär se / dat klein es

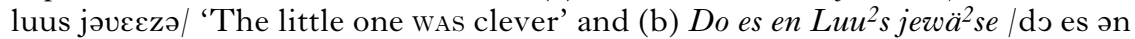

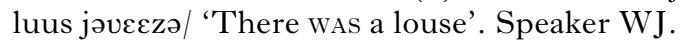

and in Fig. 6b there is mid or high level pitch for the syllable with Accent 2, the noun $L u u^{1}$ s, where the fall only starts after the vowel. ${ }^{8}$

The assumption of an underlying $\mathrm{H}$ tone cannot be maintained, however, when we consider interrogative contours. Figure 7 gives the IP-final contours for the interrogative intonation. As can be seen, both IP-final contours rise, but the rise for Accent 2 comes later in the syllable than in the case of Accent 1. In IP-internal nuclear position, the contrast shows up as a rise for Accent 1 and a level tone followed by a rise in a following syllable in the case of Accent 2 (Fig. 8). Prenuclear L*H can be observed

8 The realisation of Accent 2 on jew $\ddot{a}^{2} s e$ in both examples is that of a late peak following a rise from mid. The initial part of the syllable is still mid-pitched, due to the lower pitch on $j e-$. 

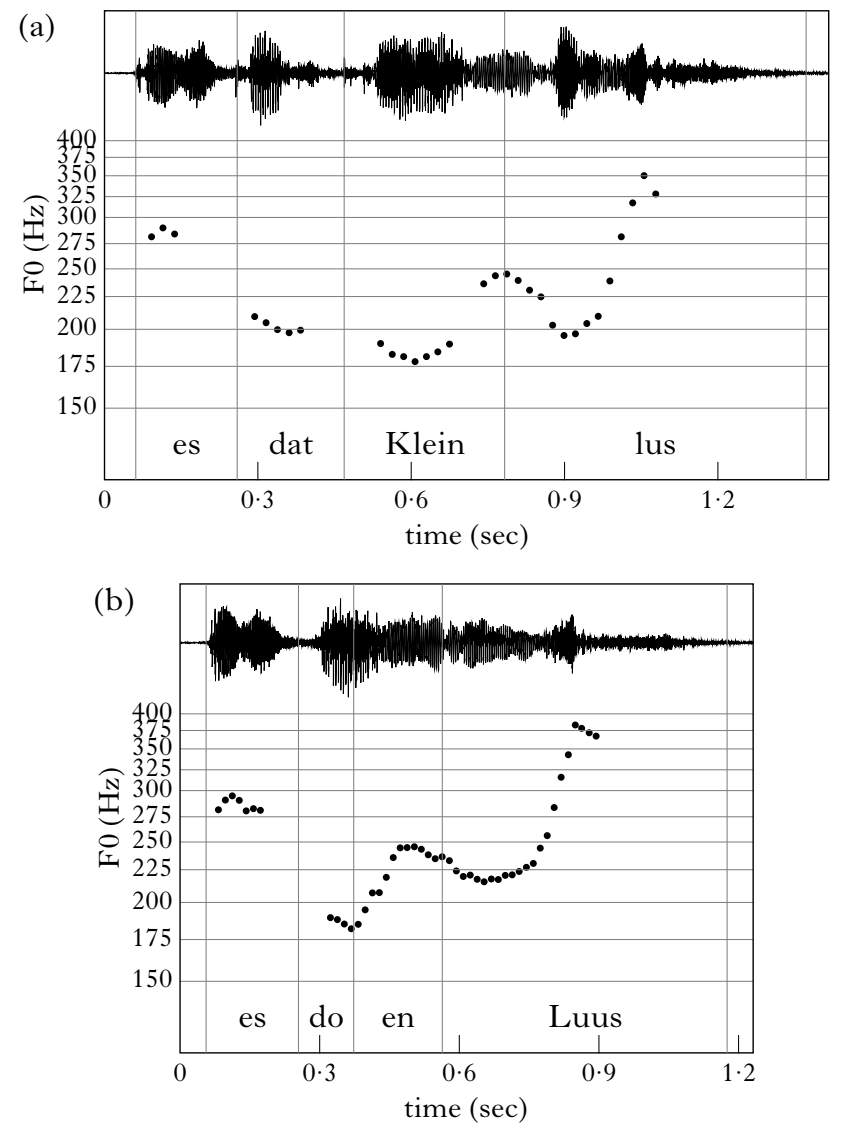

Figure 7

Speech waveforms and F0 tracks of (a) Es dat Klein ${ }^{1}$ lu $^{1}$ s? / es dat klcin luus/ 'Is the little one clever?' and (b) $E s d o^{2}$ en $L_{u u^{2}} s$ /es do ən luus/ 'Is there a louse?'. Speaker AH.

in Fig. $7 \mathrm{~b}$, where $d o^{2}$ is low-pitched, with a rise occurring through en, and in Fig. 7a, where the rise takes place inside the syllable Klein ${ }^{1}$.

Within the accented syllables, the interrogative contours thus appear to mirror the declarative contours. This suggests that Accent 1 has $\mathrm{L}^{*} \mathrm{H}$ and Accent 2 has LL*H. In both interrogative and declarative contours, the nuclear occurrences are followed by the IP-final boundary tone $\mathrm{L}_{\mathrm{i}}$. This boundary tone is truncated in IP-final nuclear syllables, but after IP-internal nuclear syllables results in the characteristic rising-falling interrogative contour also reported for the related dialects of Mayen (Schmidt 1986) and Roermond (Gussenhoven 2000a). ${ }^{9}$ The peak of a

9 In other dialects, these contours do not necessarily have the same analysis as we give here for Cologne. The Roermond interrogative is $\mathrm{L}^{*} \mathrm{H}_{\mathrm{i}} \mathrm{L}_{\mathrm{i}}$, for instance. In the 

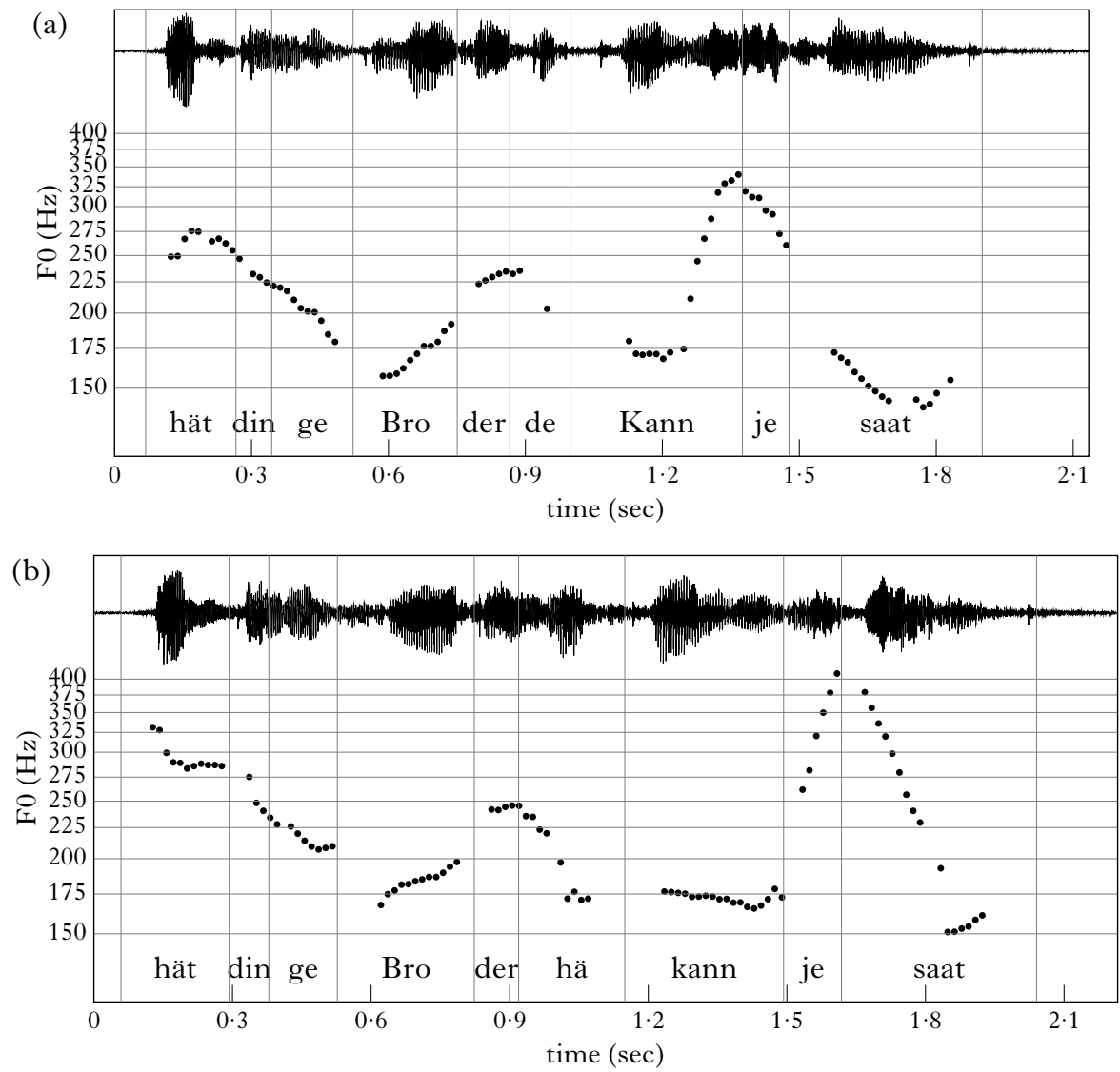

Figure 8

Speech waveforms and F0 tracks of (a) Hät dinge Bro ${ }^{1}$ der 'de Kann' ' jesaa ${ }^{2} t$ ? /het dinə broodər də kan jəzaat/ 'Did you brother say “the jug”?' and (b) Hät dinge Bro' der 'hä kann', jesaa ${ }^{2} t$ ?' / het dinə broodər heع kan jəzaat/ 'Did you brother say "he can”?'. Speaker AH.

prenuclear $\mathrm{L}^{*} \mathrm{H}$ will merge with the $\mathrm{H}$ or $\mathrm{H}^{*}$ of the next accented syllable if this has $\mathrm{H}^{*} \mathrm{~L}$, or else the $\mathrm{L}^{*} \mathrm{H}$ is followed by a fall towards $\mathrm{L}$ or $\mathrm{L}^{*}$ if the

dialect of Roermond, the lexical tone appears in IP-final position if the Accent-2 syllable is IP-final. Application of the analysis proposed here for Cologne to Roermond implies that we would need a mechanism to account for the variation between IP-internal nuclear $\mathrm{TL}^{*} \mathrm{H} \ldots \mathrm{L}_{\mathrm{i}}$ and IP-final nuclear $\mathrm{L}^{*} \mathrm{HL}_{\mathrm{i}} \mathrm{T}$ (where $\mathrm{T}$ is the lexical tone which must assimilate to $\mathrm{L}^{*}$ in the IP-internal case but appears as $\mathrm{H}$ in the IP-final case). In addition, some provision would be needed to assimilate the trailing $\mathrm{H}$ tone to $\mathrm{L}^{*}$ in the IP-final case, since the surface manifestation of the IP-final contour is $\mathrm{L}^{*} \mathrm{LL}_{\mathrm{i}} \mathrm{H}$. This latter assimilation would be otherwise unmotivated. By contrast, in the analysis of the Roermond dialect in Gussenhoven (2000a), the assimilation of the lexical tone and the assimilation of $\mathrm{H}_{\mathrm{i}}$ are contextually indistinguishable, and are accounted for in the same way. 
next accented syllable has $\mathrm{L}^{*} \mathrm{H}$. In (14), we give the representations of the expressions in Fig. 7.

(14) a. \{es dat klcin luus \}

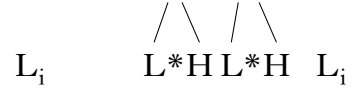

b. $\{$ es doว ən luus $\}$

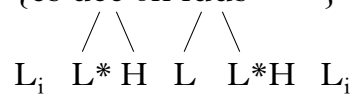

Our impression is that the accentuation of prenuclear words is variable, as it is in the standard language. Equally, accented prenuclear lexical words may have $\mathrm{L}^{*} \mathrm{H}$ or $\mathrm{H}^{*} \mathrm{~L}$ independently of the nuclear pitch accent. For instance, in both Figs $5 \mathrm{a}$ and $5 \mathrm{~b}$, prenuclear $B r o^{1}$ der has $\mathrm{H}^{*} \mathrm{~L}$ occurring before $\mathrm{L}^{*} \mathrm{H}$. Again, this variation between different pitch accents in prenuclear position also occurs in the standard language. We assume that there are pragmatic correlates, but this issue is of no concern to us here.

In the continuative utterances, we observed a number of nuclear patterns, including the two contours treated above. A third contour shows level pitch after the nuclear syllable, which itself is pronounced with $(\mathrm{L}) \mathrm{L}^{*} \mathrm{H}$. Interestingly, no rise appears in the case of IP-final Accent 2, which has mid level pitch throughout. We compare Accent 1 and 2 in this IP-final position in Fig. 9, where (a) illustrates a rising $/ \mathrm{kan} / \mathrm{Kann}{ }^{1}$ 'jug' and (b) a mid level $/ \mathrm{kan} / \mathrm{kann}^{2}$ 'can'. In IP-internal position, both word accents are followed by a rise, but in both cases this rise represents a step up to a highish level pitch, a contrast shown in Fig. 10. The contours are accounted for by assuming that Accent 1 has $\mathrm{L}^{*} \mathrm{H}$ and Accent 2 has $\mathrm{LL}^{*} \mathrm{H}$, as in the interrogative contour, with the proviso that $\mathrm{H}$ is truncated in IP-final position (Fig. 9b). The difference with the interrogative contour is in the absence of a boundary tone. The representation of the continuative contour in Fig. 10b, for instance, is given in (15).

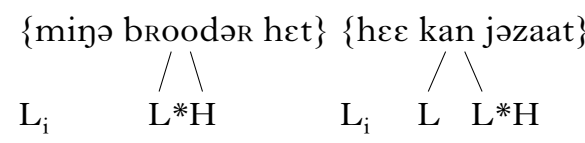

Finally, it is noteworthy that the F0 of the level pitch in Accent-2 syllables, corresponding to LL, varies greatly. In some cases it is fully low, but in other cases is considerably higher, though always below the target of the immediately following $\mathrm{H}$ tone. Arguably, therefore, instead of LL*H the contour could be analysed as $\mathrm{HH}^{*} \mathrm{H}$, if the phonetic implementation were to specify that the first two $\mathrm{H}$ tones are pronounced lower than the trailing $\mathrm{H}$ tone. Similar variation can be observed in the case of Accent 1, which would under this option be analysed as the pitch accent $\mathrm{H}^{*} \mathrm{H}$ instead of $\mathrm{L}^{*} \mathrm{H}$. The two rises in Fig. 7a show this variation within the same contour. 

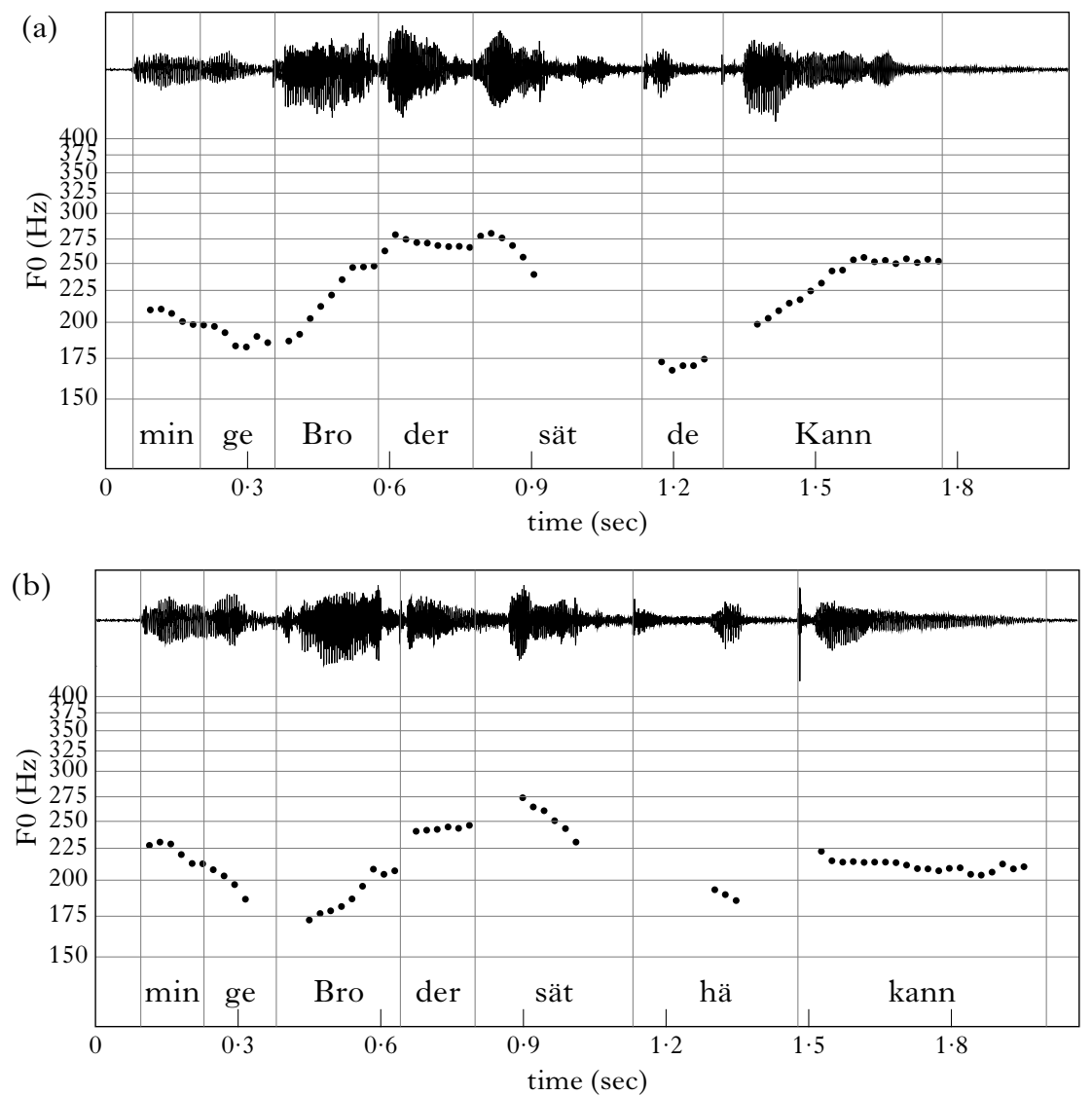

Figure 9

Speech waveforms and F0 tracks of (a) Minge Bro'der sät 'de Kann' ' /minə

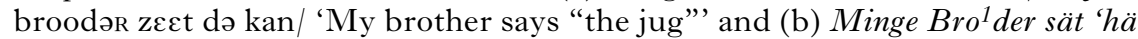

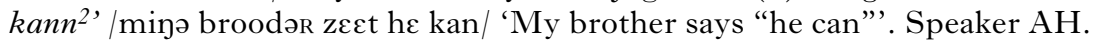

This alternative L-less analysis has two drawbacks. First, a phonetic implementation rule that lowers $\mathrm{HH}^{*}$ before $\mathrm{H}$ (Accent 2 ) and $\mathrm{H}^{*}$ before $\mathrm{H}$ (Accent 1) would be somewhat unexpected. Downstepping is typically sensitive to lefthand contexts, H or HL. A second drawback is that the phonetic lowering of $\mathrm{H}$ would be unexpectedly extreme in those cases where the interrogative rise starts at fully low pitch. A description whereby a tone's value is phonetically realised as if it were its opposite strikes us as undesirable, even though the latitude between a phonological feature and its phonetic implementation has not, as far as we know, been subjected to any kind of constraining analysis. ${ }^{10}$

${ }^{10}$ For an experimental approach to the issue of $\mathrm{H}^{*}$ vs. $\mathrm{L}^{*}$, see Gussenhoven \& Rietveld (2000). 

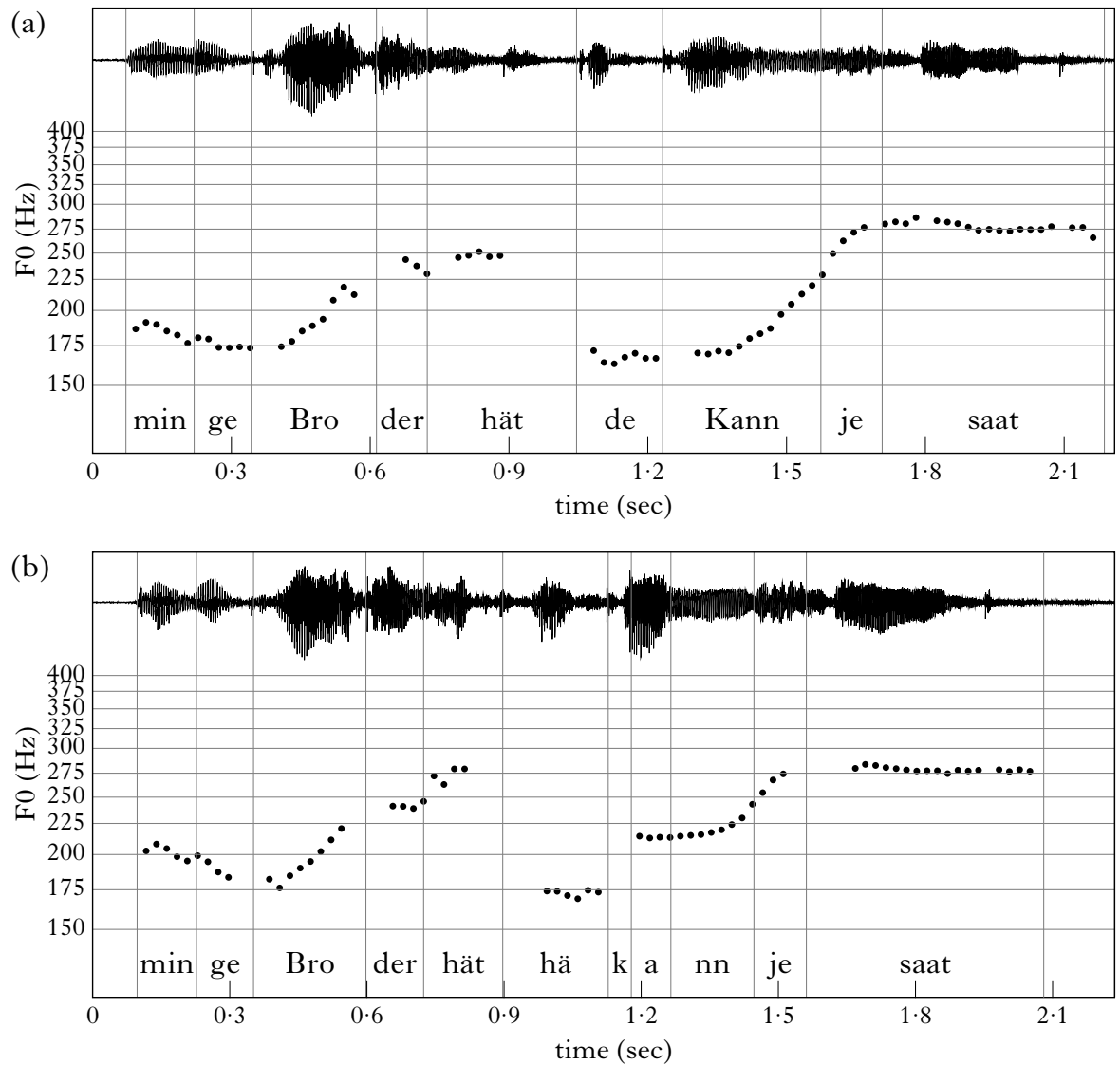

Figure 10

Speech waveforms and F0 tracks of (a) Minge Brolder hät 'de Kann ${ }^{1}$ ' jesaa ${ }^{2} t$ /minə broodər het də kan jəzaat/ 'My brother said "the jug"' and (b) Minge Brolder hät 'hä kann'”' jesaa't /mijə broodər het he kan jezaat/ 'My brother said "the jug"'. Speaker AH.

We summarise the preliminary tonal structures as in (16).

Accent $1 \quad$ Accent 2

$\begin{array}{lll}\text { Fall } & \mathrm{H}^{*} \mathrm{~L} \mathrm{~L}_{\mathrm{i}} & \mathrm{HH}^{*} \mathrm{~L} \mathrm{~L}_{\mathrm{i}} \\ \text { Rise-Fall } & \mathrm{L}^{*} \mathrm{H} \mathrm{L} \mathrm{L}_{\mathrm{i}} & \mathrm{LL}^{*} \mathrm{H} \mathrm{L}_{\mathrm{i}} \\ \text { Level } & \mathrm{L}^{*} \mathrm{H} \varnothing & \mathrm{LL} \mathrm{L}^{*} \mathrm{H}^{-}\end{array}$

As will be clear, in a tonal analysis Accent 2 has one tone more than Accent 1 , the lexical tone. It precedes the intonational pitch accent $\left(\mathrm{H}^{*} \mathrm{~L}\right.$ or $\left.\mathrm{L}^{*} \mathrm{H}\right)$, and assimilates to the next tone. In (16) and elsewhere, the asterisk is used to indicate the first tone of the intonational pitch accent. 
In the next section, we consider the contrast without an intonational pitch accent. The question here will be whether a lexical tone can be observed in isolation from the intonational pitch accent and if so, what its value is.

\subsection{The word-accent contrast after the nuclear syllable}

As observed in $\$ 4.1$, tonal dialects vary in the maintenance of the contrast outside accented syllables. In the dialect of Maastricht, which abundantly employs lengthening of Accent-2 syllables as a way of enhancing its tone contrast, the opposition remains intact outside accented syllables (Gussenhoven \& Aarts 1999), while in the nearby dialects of Tongeren and Hasselt, both spoken in Belgium, the opposition is maintained even without such abundant durational enhancement (Heijmans 1999, Peters, $\mathrm{ms})$. In contrast, the dialects of Venlo and Roermond maintain it only if the unaccented syllable is IP-final (Gussenhoven \& van der Vliet 1999, Gussenhoven 2000a).

In order to appreciate the predicament posed by the Cologne postnuclear data, a brief look at the realisation of the postnuclear contrast in the dialect of Maastricht is instructive. Despite its reliance on durational enhancement, the Maastricht dialect provides unambiguous tonal data in postnuclear syllables. In Fig. 11, we show postnuclear pronunciations of $e i^{1} k e$ 'egg-DIM' and $e i^{2} k e$ 'oak', after a falling intonation on a preceding word. While the fall of the contour in (a) reaches a low F0 fairly quickly, that in the contour in (b) shows a F0 peak in the stressed syllable of the postnuclear word. In this case, an analysis whereby Accent 2 has a lexical $\mathrm{H}$ tone and Accent 1 is toneless is straightforward. The postnuclear pitch peak in the Maastricht contour in Fig. 11b would typically be interpreted as a pitch accent by speakers of standard Dutch, even though it represents an unaccented pronunciation.

In the Cologne dialect, the distinguishing phonetic feature in the realisation of the postnuclear contrast is duration. Postnuclear stretches sound deaccented, also to speakers of standard German and Standard Dutch. Nevertheless, on the basis of a visual inspection of the F0 tracks, such syllables often appear to bear pitch accents that are scaled down relative to nuclear and prenuclear pitch accents. The observation that postnuclear stressed syllables may manifest themselves as F0 contours that replicate in miniature the F0 contours of their accented counterparts is not new. With reference to the Cologne dialect, Heike (1964: 112) observes that secondarily stressed $\mathrm{Huu}^{1}$ s 'house + SG + DAT' carries features of Schärfung, although usually less clearly so than in stressed Mü̈̈s 'mouse + PL + NOM', in a sentence like Wi han Müs im Hus 'We have mice at home'. Similarly, in her description of the intonation of American English, Pierrehumbert (1980: 124ff) refers to postnuclear word stresses as 'echo accents', and describes them as miniaturised replicas of the nuclear accent. Rietveld (1983) introduces the notion of halve klemtoon 'half stress', found on syllables with minor F0 obtrusions which in his 

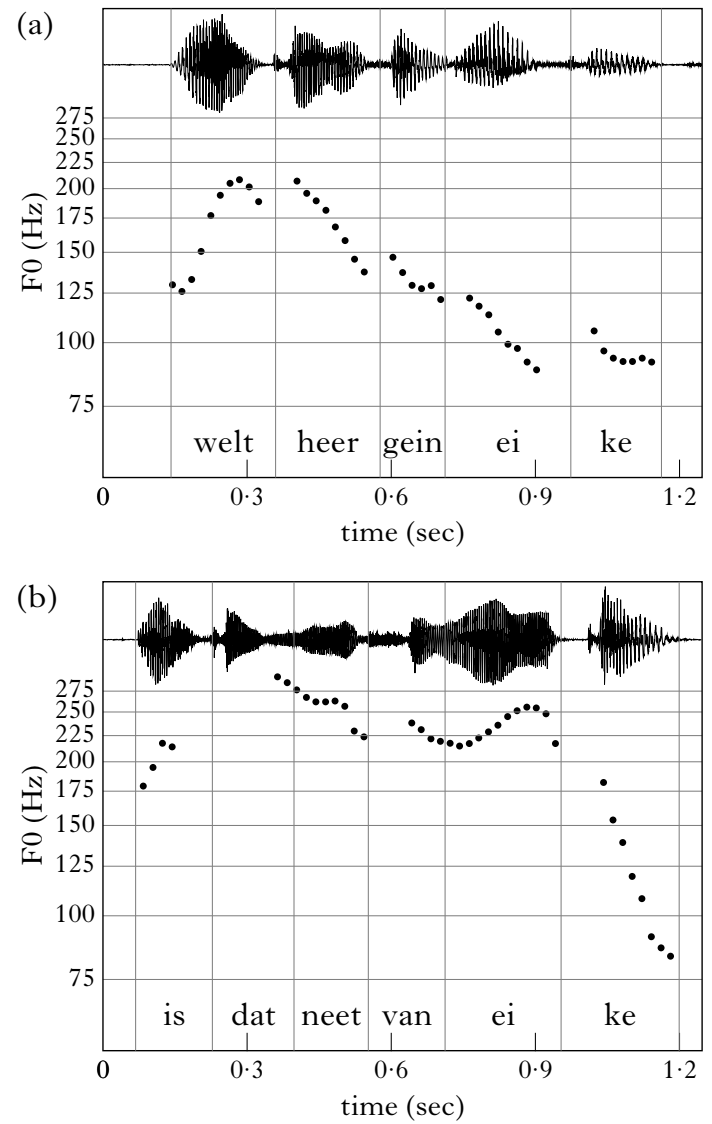

Figure 11

Speech waveforms and F0 tracks of (a) Welt heer gein ei ${ }^{1} k e /$ welt heen yein cikə/ 'Doesn't he WANT to have an egg?' and (b) Is dat neet van ei ${ }^{2} k e$ / Is tat neet faan cikə/ 'Isn't that made of oak?' in the dialect of Maastricht (data from Gussenhoven \& Aarts 1999; Speaker FA).

judgement do not correspond to any of the accenting pitch movement of 't Hart \& Collier (1975), adding that 'it is conceivable that word stresses in [second constituents of] compounds continue to manifest themselves with the help of pitch movements' (1983: 48; translation CG/JP). Current theory is not equipped to explain the occurrence of these miniaturised pitch accents, which cannot always be interpreted as copies of adjacent tones or of associations of boundary tones (cf. Grice et al. 2000), but which may well find a place in an exemplar-based account of phonetic implementation (cf. Pierrehumbert 2002). What is important in the context of our research question is that the lexical tone contrast in the Cologne dialect is preserved after the nuclear accent, and the postnuclear word accents not infrequently reproduce the specific pitch contours of the 

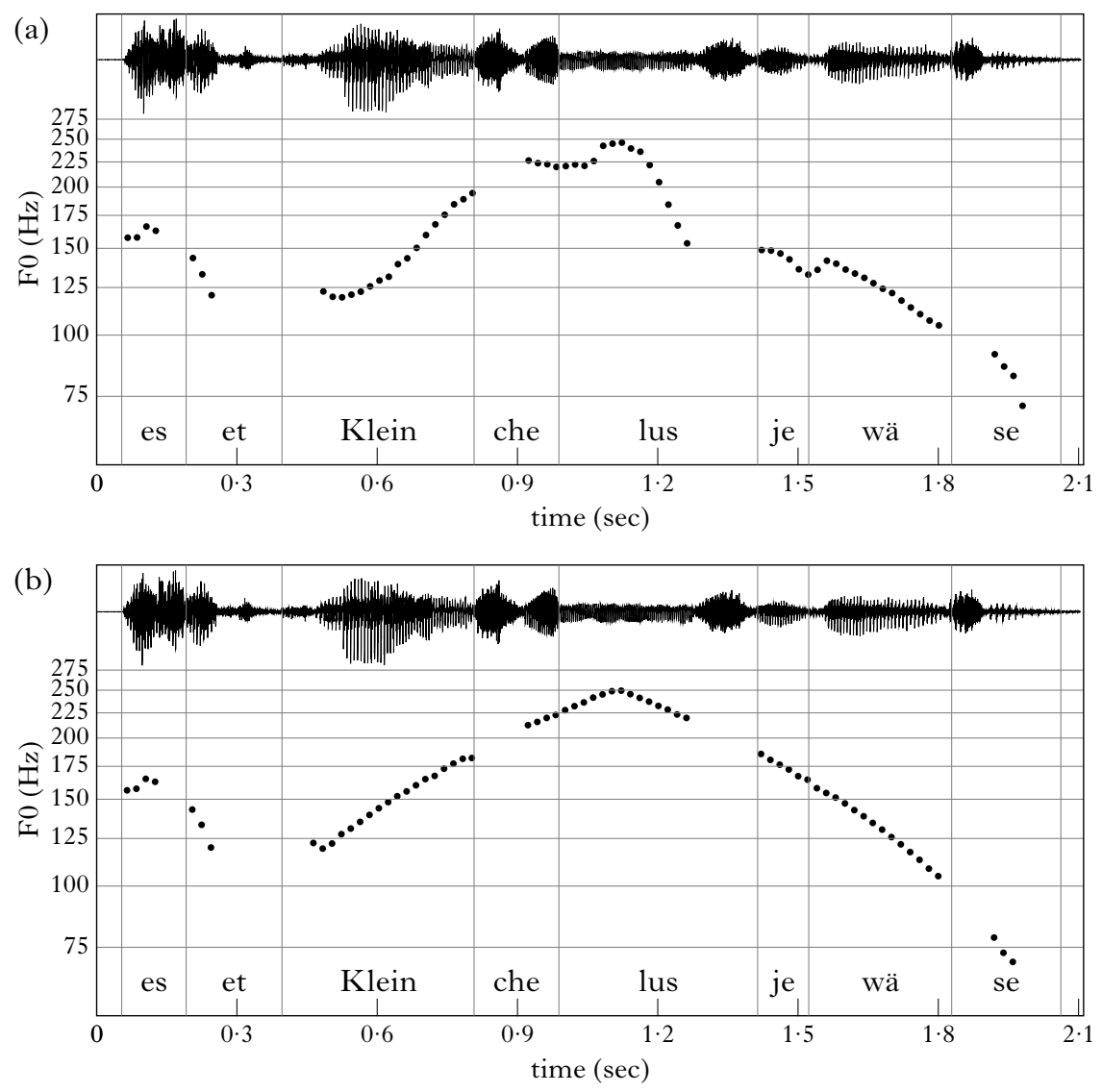

Figure 12

Speech waveform and F0 track of (a) Es et Klei $i^{1} n c h e l u^{1}$ s jewä $\ddot{a}^{2}$ se / es at kleint fe

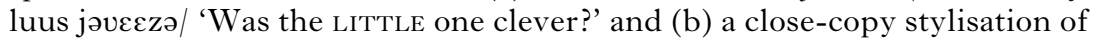
the same contour. Speaker WJ.

pitch-accented versions, as illustrated in Fig. 12a, where $l u^{1} s$ has Accent 1 and jew $\ddot{a}^{2}$ se Accent 2.

Thus, on the one hand the lexical tone contrast is maintained after the nuclear accent, necessitating the presence of a lexical tone in the representation, but on the other, because of the miniaturised character of the pitch events concerned, there is no unambiguous tonal event of the type illustrated in Fig. 11b, which could motivate a choice between $\mathrm{H}$ and $\mathrm{L}$. In all postnuclear cases, the words in question lie along the general trajectory of a slope or level stretch of pitch after the nuclear syllable, and do not appear to contribute to the shape of the contour. To verify that the miniaturised word-accent shapes are not linguistically significant, we applied the research technique used by the 'Dutch School' ('t Hart et al. 1990: 42). We resynthesised the contour in Fig. 12a, using close-copy stylisation 


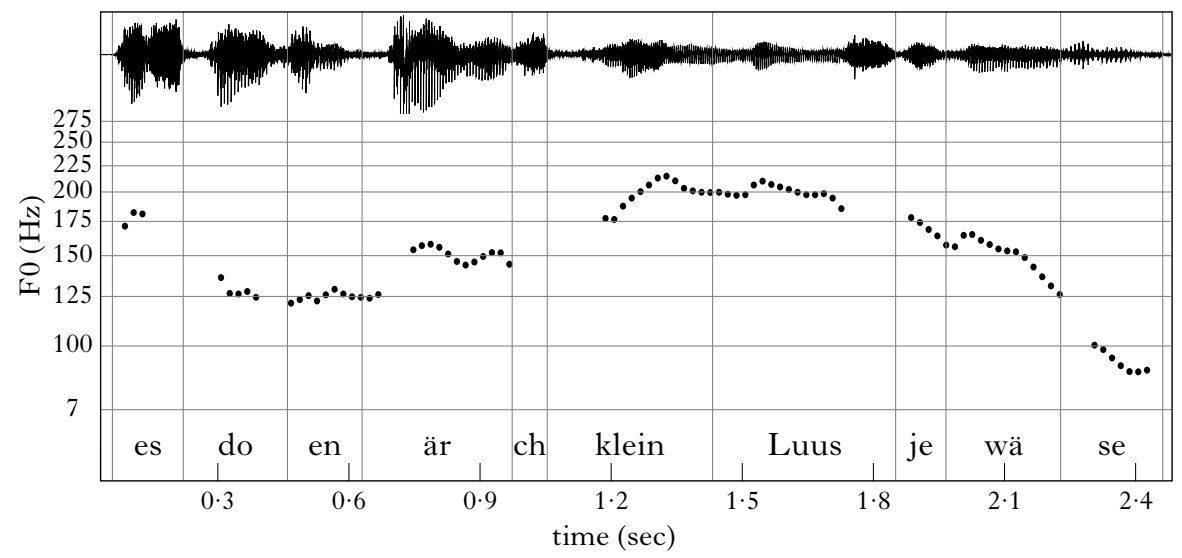

Figure 13

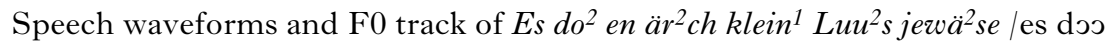

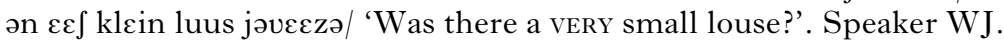

as shown in (b), and asked a native speakers of the dialect, speaker $\mathrm{AH}$, whether she heard a difference between the original and the close copy. We did the same with two other contours with early nuclear syllables. In all three cases, no difference was heard, confirming our own impression.

Taken by itself, the fact that the Cologne dialect maintains the wordaccent contrast in postnuclear positions while not revealing the presence of the lexical tone in the F0 contour is an argument for a quantity analysis of the contrast. Since there are no obvious F0 effects in the signal, how could a tone be there in the representation? We found considerable variation in the way postnuclear lexical tones are pronounced. After $\mathrm{H}^{*} \mathrm{~L}$, the postnuclear stretch may fall slowly towards the IP end, but equally it may fall more rapidly and be quite flat. Similarly, in interrogative contours, the postnuclear part of the contour may fall immediately after the rise, due to $\mathrm{L}^{*} \mathrm{H}$, but may equally remain high until inside the last stressed syllable. But since the evidence against a quantity analysis is so strong, we cannot avoid the conclusion that the contrast in postnuclear words is tonal.

Two solutions would appear to be possible. First, the lexical tone, which obviously assimilates to the intonational $\mathrm{T}^{*}$ in accented syllables, may also be assumed to assimilate after the nucleus to the tone on its left, i.e. the trailing tone of the preceding pitch accent. Under this option, the representation of the contour in Fig. 12 is $\mathrm{L}_{\mathrm{i}} \mathrm{L}^{*} \mathrm{H} \mathrm{H} \mathrm{L} \mathrm{L}_{\mathrm{i}}$, where the lexical tone on jew $\ddot{a}^{2}$ se is $\mathrm{H}$, because the pitch accent on Klein che is $\mathrm{L}^{*} \mathrm{H}$. Similarly, in declarative contours, the postnuclear lexical tones appear as L. A second option would be to allow the unspecified value of the tone to persist in the surface representation after the nucleus. This option implies the existence of an empty tonal node whose phonetic implementation consists in a lengthening of the syllable it is associated with. This solution is shown in (17a) for the contour in Fig. 13 (cf. Yip 1989), where H stands 
just for the feature specification [+high tone], with the segment being represented by the tonal tone. This representation is to be compared with that in (17b), the first solution, in which the postnuclear lexical tone acquires the value of the trailing tone of the preceding pitch accent. Since that tone, other than in Accent-1 syllables, is not itself associated, we cannot assume that it spreads in the usual way to TBUs. Here, we would assume that the feature [ $\alpha$ high tone] spreads to empty lexical tonal nodes, as shown in (17b). There is not much to choose between these solutions, but we will adopt a shorthand notation of (17b) in the remainder of this article.

(17) a. \{es doว ən $\left.\varepsilon \varepsilon \int k l \varepsilon i n ~ l u u s ~ j ə u \varepsilon \varepsilon z ə\right\}$

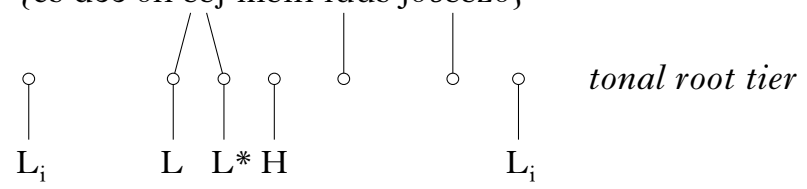

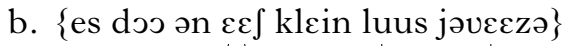

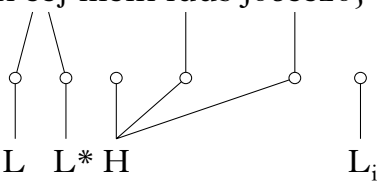

tonal root tier

\subsection{Moraic tone-bearing units}

Finally, we present evidence for the moraic nature of the tone-bearing unit (TBU). First, the absence of the lexical tone contrast in stressed syllables with one sonorant mora immediately follows from the assumption that the lexical tone must leave one TBU free for an intonational pitch accent to associate with. As in the dialects of Roermond and Venlo, there is additional evidence to be found in the pitch contours in monomoraic syllables. As we have seen, the slope of the declarative $\mathrm{H}^{*} \mathrm{~L}$ pitch accent is generally quite steep for Accent 1, but the falls are later, and often also less steep, after pitch-accented syllables with one sonorant mora as well as after syllables with Accent 2. These facts are accounted for by the TBU that becomes available to the trailing $\mathrm{L}$ tone in the case of Accent 1 . By contrast, in syllables with one sonorant mora, the only TBU is associated with $\mathrm{H}^{*}$, while in the case of Accent 2 the two TBUs are associated with lexical $\mathrm{H}$ and $\mathrm{H}^{*}$, respectively. Figure 5a shows the steep fall in $\mathrm{brau}^{1} t$, while Fig. 5b shows the level high for Accent 2. The fall after a syllable with one sonorant mora is shown in Fig. 14. In (18), the associations for these three syllables are shown, with idealised implementations. For the dialects of Venlo and Roermond the differences between Accent 1 on the one hand and monomoraic syllables and syllables with Accent 2 on the other have been shown to be present in the postnuclear slope (Gussenhoven \& van der Vliet 1999, Gussenhoven 2000c). The 


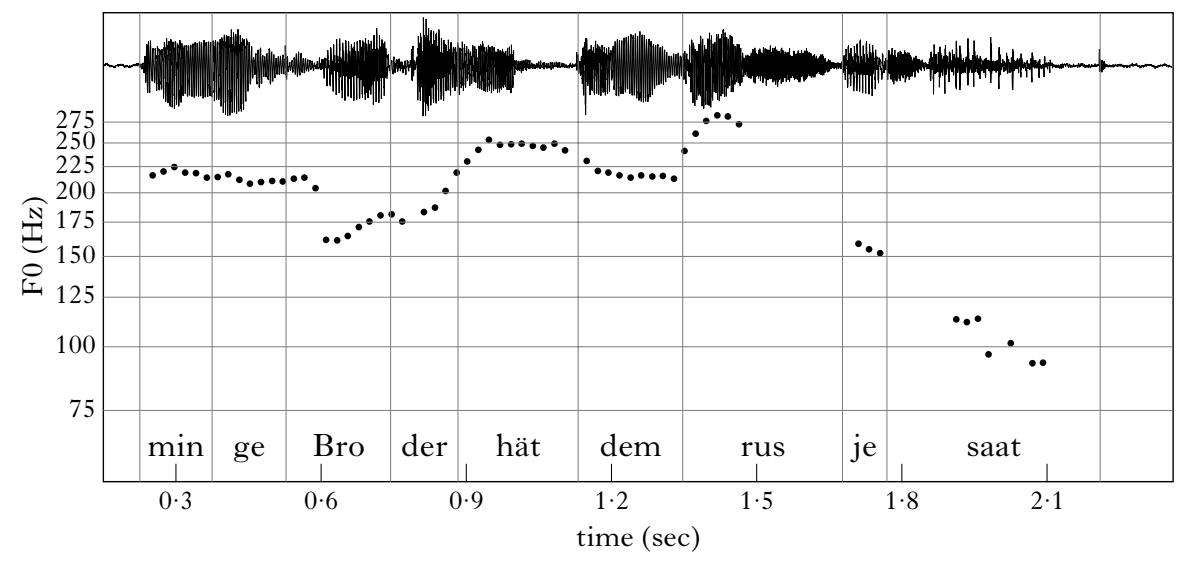

Figure 14

Speech waveform and F0 track of Minge Bro' der hät 'dem Rus' jesaa ${ }^{2} t /$ minə broodər het dəm rus jəzaat/ 'My brother said “the-DAt Russian”'. Speaker AH.

situation for the interrogative/continuative pitch accent $\mathrm{L}^{*} \mathrm{H}$ is entirely parallel.

(18) a.

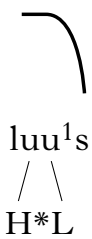

b.

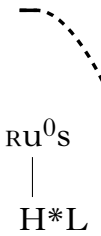

c.<smiles>CCC</smiles>

$\mathrm{luu}^{2} \mathrm{~s}$<smiles>C1CC1</smiles>

$\mathrm{H} \quad \mathrm{H} * \mathrm{~L}$

\section{Historical and typological aspects}

The question arises as to what made this tonal contrast look so durational. Might it originally have been a quantity contrast? On the grounds of its political and cultural importance, it is widely believed that the dialect of Cologne is the originator of the word-accent contrast (de Vaan 1999, Gussenhoven 2000b, Schmidt 2002). If it started out as a quantity contrast, it would be hard to see what made the speakers of the neighbouring dialects reinterpret the ternary system as a binary system plus tone. ${ }^{11}$ The circumstantial evidence, therefore, supports a tonal analysis, in line with what we concluded on language-internal grounds.

We assume that the contrast was originally implemented largely with the help of durational differences, and increasingly revealed its tonal

11 The only dialects that have a quantity contrast which corresponds etymologically with the word-accent contrast of tonal dialects have been reported in the periphery of the tonal area (Cajot 2001, Heijmans 2003). 


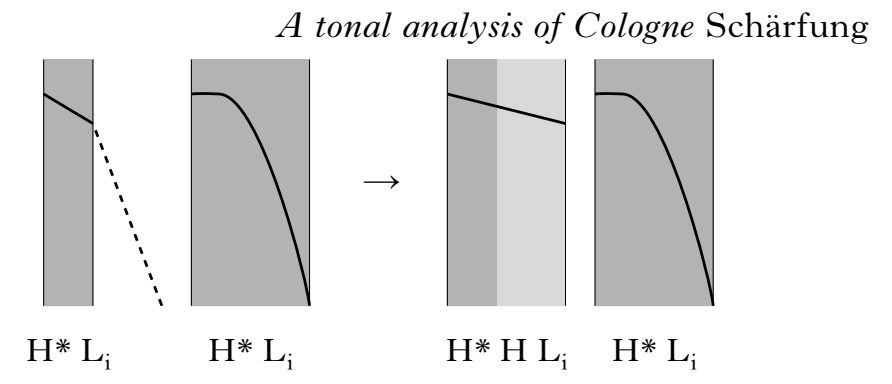

Figure 15

Hypothesised Fake Analogical Lengthening. To the left of the arrow, a monosyllabic singular form with a short vowel and monosyllabic plural form with a long vowel are given with an idealised falling intonation contour, as would occur in IP-final position. To the right, the result of non-neutralising lengthening is shown as a tonal interpretation.

nature only in subsequent developments. In this view, the Cologne dialect represents a conservative stage relative to the superficially more tonal dialects spoken in the Netherlands and Belgium. This scenario is plausible given the account of the tonogenesis proposed in Gussenhoven (2000b), which claims that the lexical tone developed in monosyllabic words with Accent 2 as a result of a predicament that arose when speakers were confronted with an incoming sound change that could not be implemented without neutralising morphological contrasts on a large scale. Before the tonogenesis, Open Syllable Lengthening had lengthened vowels in binary feet, VCə $\rightarrow$ VVCə (Lahiri \& Dresher 1999), which led to alternations between monosyllabic stems with short vowels, like nominative singulars, and inflected bisyllabic forms with long vowels, like plurals and dative singulars. Dutch still has some thirty singular $\sim$ plural pairs of this type, like weg $\sim$ wegen $/ \mathrm{v} \varepsilon \chi \sim$ ve: $\chi \partial /$ ' $\mathrm{road}$ ', lot $\sim$ loten / lot $\sim$ lo:tə/ 'lottery ticket', dal $\sim$ dalen /dal $\sim$ da:lə/ 'valley'. Speakers were subsequently confronted with apocope (deletion of word-final schwa) on the one hand and analogical lengthening on the other, which replaced the short vowel in the monosyllabic forms with the new long vowel from the inflected forms. Analogical lengthening was applied quite generally in the precursor of standard German (Weg Wege/ve:k vergə/, etc.), but if we assume that the Cologne dialect had apocopated its inflected forms by the time analogical lengthening arrived, its speakers will have resisted lengthening the vowel of the nominative singulars, as this would have neutralised the distinctions between nominative singulars on the one hand and plurals and dative singulars on the other.

The response to the predicament was to lengthen the short-vowel singular monosyllabic forms, without allowing them to become homophonous with the plural long-vowel monosyllabic forms. The resulting drawled singulars were phonologically interpreted as having a HHL contour, which contrasted with the (declarative) HL contour of the plurals. This is shown schematically in Fig. 15. The Cologne data confirm this 


\section{8}

\section{Carlos Gussenhoven and Förg Peters}

scenario in an interesting way. While the contrast was interpreted as tonal right from the start, the original phonetic lengthening has been preserved on the surface. As the contrast spread to the wider Central Franconian area, its tonal nature became more apparent. The Maastricht dialect, relying as it does on duration for the enhancement of the contrast but clearly showing the tone in postnuclear words, is a halfway house between Cologne and Roermond, the latter dialect being entirely tonal in the sense that no obvious durational difference between Accent 1 and Accent 2 is made.

The hypothesis in Fig. 15 needs to be revised in one respect. In Gussenhoven (2000b) it was assumed that the lexical tone was identified as the second of the two $\mathrm{H}$ tones, as shown by the starred intonational $\mathrm{H}^{*}$. This reconstruction was inspired by the analyses of the Maasbracht, Roermond and Venlo dialects, which have the 'extra' tone on the second mora of the stressed syllable of words with Accent 2 (Hermans 1985, Bruce \& Hermans 1999, Gussenhoven \& van der Vliet 1999, Gussenhoven 2000a). While those analyses are well motivated in that respect, there is little reason for assuming the same analysis for Cologne: it would gratuitously require the pitch accents $\mathrm{H}^{*} \mathrm{~L}$ and $\mathrm{L} * \mathrm{H}$ to be split up by the lexical tone. $^{12}$

A reviewer has pointed out that our account assumes that speakers can step in to prevent mergers from happening, an assumption that may be uncomfortably teleological. One defence here is that the threatened merger was morphological - that of number (singular and plural) as well as case (nominative and dative) - and needs to be put in the wider perspective of the measures that were taken to cope with the threat of those same mergers in other dialects. Wiesinger (1983) mentions suspension of final devoicing, as occurred in High Prussian and Yiddish, which caused plurals to be distinct from singulars in having a [+voice] coda consonant, contrasting with the [-voice] consonant in the coda. While voiced final consonants may also have appeared in words that did not have otherwise identical forms with voiceless consonants in their paradigm, the imminent morphological mergers that would have materialised if final devoicing had gone through must have acted as a force against it. As in the case of the Central Franconian tone, final voiced obstruents in surface forms represented a novel phonological element in the language. In another case, unetymological umlauts were created for plural forms, as in Hund Hünd 'dog dogs' (Dingeldein 1983; cf. also Gussenhoven 2000b: 230).

12 Heijmans (1999) analysed the Tongeren dialect (Belgium) as having the lexical tone in first position. The Tongeren declarative and interrogative Accent-2 nuclear contours in that analysis are LLH and LHL, respectively, as opposed to LH and HL for Accent 1. The simplest morphological decomposition is to assume that the lexical tone is $\mathrm{L}$, and occurs before the pitch accents $\mathrm{L}^{*} \mathrm{H}$ and $\mathrm{H}^{*} \mathrm{~L}$. While this makes the Tongeren tonal system the perfect inversion of that of Cologne, it does suggest that the association of the lexical tone to the second mora is a later development in the north-western corner of the tonal area. 
Assuming, then, that speakers may have acted so as to prevent the morphological mergers that arose after apocope, the further assumption is that they must have done so by 'slurring' the pronunciation of short vowels, a creation of fake long vowels. That is, the question could be asked whether there might have been a less dramatic ploy to keep the morphological distinctions intact while at the same time simply adopting long vowels in singular nominatives as bimoraic vowels, just like the speakers they were imitating. However, a refusal to adopt the obvious phonological analysis of a borrowed form is not unusual either. For instance, the declarative Accent-2 contour in IP-final syllables in the dialect of Venlo, which borders on toneless dialects to its north and east and to tonal dialects to its south and east, is a compromise between the Roermond-type fall-rise, $\mathrm{H}^{*} \mathrm{~L}_{\mathrm{i}} \mathrm{H}$, and a fall, analysed as $\mathrm{H}^{*} \mathrm{~L} \mathrm{~L}_{\mathrm{i}}$ for the standard language. The Venlo compromise is a fall to not-quite-low, one that falls and then levels off, analysed by Gussenhoven \& van der Vliet (1999) as $\mathrm{H}^{*} \mathrm{~L} \mathrm{~L}_{\mathrm{i}}$, where the $\mathrm{L}$ tone is a lexical tone. Arguably, the Venlo speakers were careful not to adopt the full-fledged phonetic form of the Roermond fall-rise, not only because it might have been too different from that of their northerly neighbours, but also because the fall-rise was in use as a question intonation for IP-final Accent-2 syllables. Thus, while motivations may vary, approximate adoption of prestigious phonetic forms cannot be unusual.

There are a number of phenomena in the wider context of the European languages which in some way resemble the Cologne word-accent contrast. These include cases of trimoraic systems, the Scandinavian word-accent contrast and Danish stød. ${ }^{13}$ None of these is historically related to it. First, the Cologne word-accent contrast differs from the ternary quantity contrasts of Estonian or northern Low German. Estonian developed the trimoraic sonorant rhymes shown in (1c) from disyllabic structures through syncope or apocope (cf. Hayes 1995: 320). The earlier binary vowel-quantity contrast was increased with the third term when the quantity of weak syllables was incorporated into the preceding stressed syllable. Nor is the Cologne contrast comparable to the Überlänge of northern Low German dialects in the Hamburg area, pace Ternes (1981). There, the trimoraic case arose as a reinterpretation of phonetic lengthening before voiced obstruents. When these had come to occur at the word end as a result of apocope, the contrast with voiceless obstruents was maintained in large parts of northern Germany. In the Hamburg case, there is no F0 difference to be noted other than what could be expected on the basis of the durational facts (Kohler et al. 1984). As a result of this development, trimoraic vowels only appear before obstruent codas, a telltale distributional fact. Indeed, the durational difference between nominative singulars and plurals or dative singulars is the reverse of that found

13 We will not consider the question whether, at some more general level of phonetic behaviour, the phenomena mentioned in this paragraph, along with the wordprosodic differences in Gaelic (Ladefoged et al. 1998), South Slavic, Lithuanian and Latvian (cf. van der Hulst et al. 1999), are manifestations of some common element. 
in Cologne, as is to be expected on the basis of the different developments. The dative form of the word for 'house' is [haius] in north German, with reinterpreted quantity due to long duration in earlier [havz(ə)], while the nominative is [haus]; in Central Franconian the dative is - or was until recently-[huus], with Accent 1, contrasting with the longer Accent-2 nominative (cf. Ternes 1981). ${ }^{14}$

The Central Franconian lexical tone is phonologically comparable to the Scandinavian contrast between Accent 1 and Accent 2. East Norwegian resembles the Cologne dialect more than does Stockholm Swedish. Although Kristoffersen (2000), following Fretheim \& Nilsen (1991), analyses the East Norwegian contrast as L (Accent 1) vs. HL (Accent 2), plus a following focal $\mathrm{H}$ tone in each case, the tone sequences $\mathrm{LH} v s$. HLH could equally be parsed into an initial lexical $\mathrm{H}$ tone followed by an intonational pitch accent $\mathrm{L}^{*} \mathrm{H}$ (Gussenhoven 2004: 220). That is, both languages can be characterised as having a privative tone opposition, with Accent 2 marked by lexical tone and Accent 1 remaining lexically toneless right up to the phonological surface representation. Moreover, East Norwegian has different intonation contours for declaratives and interrogatives, thanks to different boundary tones. Stockholm Swedish employs the same phonological melody for questions and statements (Bruce 1977). East Norwegian resembles the Cologne situation, although the difference here is in the pitch accent. In addition, while the Scandinavian word-accent contrast quite generally requires a disyllabic trochee, East Norwegian also contrasts monosyllabic words underlyingly (Kristoffersen 2000). While word-final stressed syllables always surface with Accent 1, in compounds a contrast arises between monosyllabic words, as in the case of ball' 'party' and ball ' 'ball', which produce different F0 patterns in ball-eksperiment, depending on whether the meaning is 'party experiment' or 'ball experiment'. Table I lists some typological facts for Stockholm Swedish (as described by Bruce 1977), East Norwegian and the Cologne dialect. In all three cases, the order of the tones in the stressed syllable is lexical tone followed by intonational tone. In this respect, Cologne differs from the related dialects spoken in the Netherlands.

Finally, Cologne Schärfung is phonologically distinct from Danish stød, which consists in the glottalisation of (part of) the stressed vowel, without enhancement of duration or F0, other than the implicit effect of creaky

14 Kohler (2001) shows that for the high vowels there is a quality contrast between what has been claimed to be a monomoraic $v s$. bimoraic contrast, rather than a quantity contrast (e.g. Kipp/kıp/'chicken', Kiep/kip/ 'basket', Kiel /ki:l/ 'wedge'), but that the mid vowels do have three contrastive durations in Haßmoor/Kiel and Brarupholz/Angeln. In these cases, the vowel corresponding to standard high $\operatorname{lax} / \mathrm{I} /$ represents the shortest case (e.g. /dek/ 'thick', /de:k/'blanket'/, /be:it/ 'request $+3 \mathrm{sg}$ '). Diphthongs contrast, as in Braut/braut/ 'bride', /brau:/ 'brew $+3 \mathrm{sG}$ '. These facts show that these dialects have trimoraic vowels, even though, as Kohler points out, there are no minimal triplets. In addition to the earlier lenis nature of final obstruents, Kohler identifies morphemic status of final consonants as a context for trimoraicity. 
A tonal analysis of Cologne Schärfung

\begin{tabular}{|l|c|c|c|}
\hline & Stockholm Swedish & East Norwegian & Franconian \\
\hline contrast type & $\mathrm{HL}-\mathrm{H}^{*} \mathrm{~L}$ & $\varnothing-\mathrm{H}$ & $\varnothing-\mathrm{T}$ \\
\hline intonation & $\mathrm{H} \mathrm{L}_{\mathrm{i}}$ & $\begin{array}{c}\text { declarative: } \mathrm{L}^{*} \mathrm{H} \mathrm{L}_{\mathrm{i}} \\
\text { interrog.: } \mathrm{L}^{*} \mathrm{H} \mathrm{H}_{\mathrm{i}}\end{array}$ & $\begin{array}{c}\text { declarative }: \mathrm{H}^{*} \mathrm{~L}_{\mathrm{i}} \\
\text { interrog. }: \mathrm{L}^{*} \mathrm{H}_{\mathrm{i}}\end{array}$ \\
\hline $\begin{array}{l}\text { monosyllabic } \\
\text { contrast }\end{array}$ & no & in compounds: yes & yes \\
\hline order & lexical-intonational & lexical-intonational & lexical-intonational \\
\hline
\end{tabular}

Table I

Four typological characteristics in two Scandinavian varieties and the dialect of Cologne.

voice on vocal cord vibration (Basbøll 2003). Phonologically, this would be expressed by a laryngeal feature like [+constricted glottis] or [+murmur]. The decreasing intensity of Cologne German Accent-1 syllables does not sound like creaky voice or a glottal stop. The stød does resemble the lexical tone of Cologne in its distribution, however, both phenomena being restricted to syllables with two sonorant moras. Etymologically, Danish stød is generally taken to be related to the Scandinavian Accent 1, and no case for a historical connection with the Central Franconian tone can realistically be made.

\section{Conclusion}

Cologne Schärfung presents a case of a phonological feature that is ostensibly realised by the 'wrong' phonetic parameter: the enhancement feature is more salient than the primary phonetic parameter, F0, of the phonological feature, [ \pm high tone]. If the tonogenesis occurred around the thirteenth century, as most accounts have it, the tonal analysis must have been reproduced by language learners over a period of more than 700 years, despite the maintenance of salient durational cues. A number of distributional facts explain this state of affairs. Chiefly, the members of the opposition cannot be captured in terms of the structures that would arise in a quantity analysis. Additionally, the occurrence of geminate consonants in the coda and their absence in intervocalic position, which a quantity analysis would entail, is highly unusual, while the analysis of Accent-2 syllables with diphthongs or vowels before sonorant rhymes would become ambiguous. As a result, the phonetic facts that point away from a quantity analysis - the disproportionate final lengthening of Accent-2 syllables and the occurrence of contour tones in Accent-1 syllables - are maintained. The situation is not unlike that of the laryngeal contrast in English coda consonants, where a voicing contrast is abundantly enhanced by the duration distinction in the preceding sonorant 


\section{Carlos Gussenhoven and Förg Peters}

portion of the syllable rhyme (particularly so in Southern British English, cf. beat-bead, pint-pined, cent-send, etc.) in a situation where the laryngeal interpretation continues to be preferred to a quantity analysis by many generations of language learners.

\section{Appendix}

With the help of the Akademie för uns kölsche Sproch we recruited one female and five male speakers, with ages ranging between 21 and 65 years. They were presented with one experimental sentence at a time on a computer screen and asked to read it out in a natural fashion. Sentences were presented in the standard orthography of Wrede (1956-58) (see note 2), grouped per intonation contour, but otherwise randomised. Speakers were instructed to repeat each sentence as often as they liked if they felt their delivery was lacking in accuracy or confidence, and their performance was monitored by at least one of the authors. In addition to (6), we used the minimal pairs $D a^{1} c h$ 'roof + DAT' $D a^{2} c h$ 'roof + NOM' and $\mathrm{Huu}^{1} s$ 'house + DAT' $\sim \mathrm{Huu}^{2} s$ 'house + NOM', which turned out to be homophonous for all speakers. We varied (i) the discourse meaning (declarative, yes-no interrogative, continuative), (ii) the focal condition of the target word (nuclear, postnuclear, prenuclear) and (iii) the distance of the target word from the end of the IP (ultimate, penultimate, antepenultimate). As no crucial differences were found between the penultimate and antepenultimate conditions, we refer to final $v s$. non-final position only. In the declarative condition, we obtained both 'narrow' informational focus with the help of answers to a question and 'narrow' corrective focus with the help of contradictions; in the interrogative and continuative conditions, we varied the size of the focus constituent for informational focus only. For the minimal pairs $l u^{1} s \sim L u u^{2} s$, $K a n n^{1} \sim k a n n^{2}$ and $D a^{1} c h \sim D a^{2} c h$ we used 20 test sentences per word. For the remaining minimal pairs $\mathrm{brau}^{1} t \sim \mathrm{Brau}^{2} t$ and $\mathrm{Huu}^{1} \boldsymbol{s} \sim \mathrm{Huu}^{2} \mathrm{~s}$ we used 17 test sentences per word, yielding a total set of 188 test sentences. In a second session, we collected additional data from speakers $\mathrm{AH}$ and $\mathrm{WJ}$ involving words with stressed syllables having one sonorant mora, using two minimal pairs per speaker, $R u^{1} s$ 'rose' $\sim R u^{0} s s$ 'Russian + DAT' and $K \ddot{o}^{1} h l e$ 'coolness + DAT' $\sim$ $k \ddot{o}^{0} l l e$ '(they) smoulder' for speaker WJ and $R u^{1} s \sim R u^{0} s s$ and fö ${ }^{1} h l e$ '(they) feel' $\sim f_{0}^{0} l l e$ ' (they) fill' for speaker AH (who did not know k $\ddot{o}^{0} l l e$ ). We recorded 14 test sentences per word, yielding a total of 56 test sentences.

\section{REFERENCES}

Basbøll, Hans (2003). Prosody, productivity and word structure: the stød pattern of Modern Danish. Nordic Fournal of Linguistics 26. 5-44.

Besch, Werner, Ulrich Knoop, Wolfgang Putschke \& Herbert Ernst Wiegand (eds.) (1983). Dialektologie : ein Handbuch zur deutschen und allgemeinen Dialektforschung. Vol. 2. Berlin \& New York: de Gruyter.

Bhatt, Christa (2002). Kölsche Schreibregeln: Vorschläge für eine Rechtschreibung des Kölschen. Cologne: Bachem.

Bruce, Gösta (1977). Swedish word accents in sentence perspective. Lund: Gleerup.

Bruce, Gösta \& Ben Hermans (1999). Word tone in Germanic languages. In van der Hulst (1999). 605-658. 
Cajot, José (2001). Een toonloze enclave in polytoon gewaand gebied: een les in structurele fonologie? Faarboek van de Vereniging voor Limburgse Dialect- en Naamkunde 3. 71-88.

Cambier-Langeveld, Tina \& Alice E. Turk (1999). A cross-linguistic study of accentual lengthening: Dutch vs. English. FPh 27. 255-280.

de Jong, Kenneth J. (1995). The supraglottal articulation of prominence in English: linguistic stress as localized hyperarticulation. $\mathcal{F} A S A$ 97. 491-504.

Dingeldein, Heinrich J. (1983). Spezielle Pluralbildungen in den deutschen Dialekten. In Besch et al. (1983). 1196-1202.

Fikkert, Paula \& Haike Jacobs (eds.) (2003). Development in prosodic systems. Berlin \& New York: Mouton de Gruyter.

Fournier, Rachel, Jo Verhoeven, Marc Swerts \& Carlos Gussenhoven (2004). Prosodic and segmental cues to the perception of grammatical number in two Limburgian dialects of Dutch. In Bernard Bel \& Isabelle Marlien (eds.) Speech prosody 2004. Nara, Japan. 713-716.

Fox, Robert Allen \& Ilse Lehiste (1989). Discrimination of duration ratios in bisyllabic tokens by native English and Estonian listeners. $\mathcal{F P h}$ 17. 167-174.

Fretheim, Thorstein \& Randi Alice Nilsen (1991). In defense of [ \pm foc]. ESCOL '90 : Proceedings of the 7th Eastern States Conference on Linguistics. Columbus: Ohio State University. 102-111.

Grice, Martine, D. Robert Ladd \& Amalia Arvaniti (2000). On the place of phrase accents in intonational phonology. Phonology 17. 143-185.

Gussenhoven, Carlos (2000a). The lexical tone contrast of Roermond Dutch in Optimality Theory. In Merle Horne (ed.) Prosody: theory and experiment. Dordrecht: Kluwer. 129-167.

Gussenhoven, Carlos (2000b). On the origin and development of the Central Franconian tone contrast. In Aditi Lahiri (ed.) Analogy, levelling, markedness: principles of change in phonology and morphology. Berlin: Mouton de Gruyter. 215-260.

Gussenhoven, Carlos (2000c). The boundary tones are coming: on the nonperipheral realization of boundary tones. In Michael B. Broe \& Janet B. Pierrehumbert (eds.) Papers in laboratory phonology $V:$ acquisition and the lexicon. Cambridge: Cambridge University Press. 132-151.

Gussenhoven, Carlos (2004). The phonology of tone and intonation. Cambridge: Cambridge University Press.

Gussenhoven, Carlos \& Flor Aarts (1999). The dialect of Maastricht. Fournal of the International Phonetic Association 29. 155-166.

Gussenhoven, Carlos \& Peter van der Vliet (1999). The phonology of tone and intonation in the Dutch dialect of Venlo. $\mathscr{F L ~ 3 5 . 9 9 - 1 3 5 . ~}$

Gussenhoven, Carlos \& Toni Rietveld (2000). The behavior of $\mathrm{H}^{*}$ and $\mathrm{L}^{*}$ under variations in pitch range in Dutch rising contours. Language and Speech 43. 183-203.

Hart, Johan't \& René Collier (1975). Integrating different levels of intonation analysis. FPh 3. 235-255.

Hart, Johan't, René Collier \& Antonie Cohen (1990). A perceptual study of intonation : an experimental-phonetic approach to speech melody. Cambridge: Cambridge University Press.

Hayes, Bruce (1995). Metrical stress theory: principles and case studies. Chicago: University of Chicago Press.

Heike, Georg (1962). Suprasegmentale Merkmale der Stadtkölner Mundart: ein Beitrag zur 'Rheinischen Schärfung'. Phonetica 8. 147-165.

Heike, Georg (1964). Zur Phonologie der Stadtkölner Mundart: eine experimentelle Untersuchung der akustischen Unterscheidungsmerkmale. Marburg: Elwert. 


\section{Carlos Gussenhoven and Förg Peters}

Heike, Georg (1988). Zur wortunterscheidenden Funktion der rheinischen Schärfung. In Horst Haider Munske, Peter von Polenz, Oskar Reichmann \& Reiner Hildebrandt (eds.) Deutscher Wortschatz : lexikologische Studien. Berlin: de Gruyter. $677-686$.

Heijmans, Linda (1999). The representation of the Tongeren lexical tone contrast. Ms, LSA Linguistic Summer Institute.

Heijmans, Linda (2003). The relationship between tone and vowel length in two neighbouring Dutch Limburgian dialects. In Fikkert \& Jacobs (2003). 7-45.

Hermans, Ben (1985). Het Limburgs en het Litouws als metrisch gebonden toontalen. Spektator 14. 48-70.

Hulst, Harry van der (ed.) (1999). Word prosodic systems in the languages of Europe. Berlin \& New York: Mouton de Gruyter.

Hulst, Harry van der, Bernadet Hendriks \& Jeroen van de Weijer (1999). A survey of word prosodic systems of European languages. In van der Hulst (1999). 425-475.

Kohler, Klaus J. (2001). Überlänge im Niederdeutschen? In Robert Peters, Horst P. Putz \& Ulrich Weber (eds.) Vulpis adolatio: Festschrift für Hubertus Menke zum 60. Geburtstag. Heidelberg: Winter. 385-402.

Kohler, Klaus J., Regina Tödter \& Michael Weinhold (1984). Ergänzende Untersuchungen zur 'Überlänge' in der Mundart von Hassmoor (Kreis Rendsburg-Eckernförde). Arbeitsberichte Institut für Phonetik der Uniersität Kiel 23. 19-116.

Kraehenmann, Astrid (2003). Quantity and prosodic asymmetries in Alemannic: synchronic and diachronic perspectives. Berlin \& New York: Mouton de Gruyter.

Kristoffersen, Gjert (2000). The phonology of Norwegian. Oxford: Oxford University Press.

Ladefoged, Peter, Jenny Ladefoged, Alice Turk, Kevin Hind \& St. John Skilton (1998). Phonetic structures of Scottish Gaelic. Fournal of the International Phonetic Association 28. 1-41.

Lahiri, Aditi \& B. Elan Dresher (1999). Open Syllable Lengthening in West Germanic. $\operatorname{Lg}$ 75. 678-719.

Lehiste, Ilse (2003). Prosodic change in progress: from quantity language to accent language. In Fikkert \& Jacobs (2003). 47-65.

Lehiste, Ilse \& Robert Allen Fox (1992). Perception of prominence by Estonian and English listeners. Language and Speech 35. 419-434.

Lyberg, Bertil (1981). Some observations on the vowel duration and the fundamental frequency contour in Swedish utterances. FPh 9. 261-272.

Maddieson, Ian (1984). Patterns of sounds. Cambridge: Cambridge University Press.

Newton, G. (1990). Central Franconian. In Charles V. J. Russ (ed.) The dialects of Modern German : a linguistic survey. London: Routledge. 136-209.

Nooteboom, S. G. (1972). Production and perception of vowel duration : a study of the durational properties of vowels in Dutch. $\mathrm{PhD}$ dissertation, University of Utrecht.

Peters, Jörg (forthcoming). The word accent opposition in the dialect of Cologne. In Michiel de Vaan (ed.) Germanic tone accents. Wiesbaden: Steiner.

Peters, Jörg (ms). Tone and intonation in the Limburgian dialect of Hasselt. University Radboud Nijmegen.

Pierrehumbert, Janet B. (1980). The phonology and phonetics of English intonation. PhD dissertation, MIT.

Pierrehumbert, Janet B. (2002). Word-specific phonetics. In Carlos Gussenhoven \& Natasha Warner (eds.) Laboratory Phonology 7. Berlin \& New York: Mouton de Gruyter. 101-139.

Rietveld, A. C. M. (1983). Syllaben, klemtonen en de automatische detectie van beklemtoonde syllaben in het Nederlands. Nijmegen: De Witte Studentenpers.

Schmidt, Jürgen Erich (1986). Die mittelfränkischen Tonakzente (Rheinische Akzentuierung). Stuttgart: Steiner. 
Schmidt, Jürgen Erich (2002). Die sprachhistorische Genese der mittelfränkischen Tonakzente. In Peter Auer, Peter Gilles \& Helmut Spiekermann (eds.) Silbenschnitt und Tonakzente. Tübingen: Niemeyer. 201-233.

Schumacher, G. (ms). Die Lautlehre (Phonologie). Akademie för uns kölsche Sproch.

Stevens, Kenneth N. \& Samuel Jay Keyser (1989). Primary features and their enhancement in consonants. $\operatorname{Lg}$ 65. 81-106.

Ternes, Elmar (1989). The phonemic analysis of Scottish Gaelic. 2nd edn (1st edn, 1973). Hamburg: Buske.

Ternes, Elmar (1981). Über Herkunft and Verbreitung der Überlänge in deutschen Dialekten. In Wolfgang U. Dressler, Oskar E. Pfeiffer \& John R. Rennison (eds.) Phonologica 1980. Innsbruck: Innsbrucker Beiträge zur Sprachwissenschaft. 379-386.

Tiling-Herrwegen, Alice (2002). De kölsche Sproch. Cologne: Bachem.

Vaan, Michiel de (1999). Towards an explanation of the Franconian tone accents. Amsterdamer Beiträge zur älteren Germanistik 51. 23-44.

Wiesinger, Peter (1983). Die Einteilung der deutschen Dialekte. In Besch et al. (1983). 807-900.

Wrede, Adam (1956-58). Neuer kölnischer Sprachschatz. 3 vols. (11th edn, 1993). Cologne: Greven.

Yip, Moira (1989). Contour tones. Phonology 6. 149-174.

Zhang, Jie (2000). Phonetic duration effects on contour tone distribution. NELS 30:2. 775-785. 